\title{
Systemic Risk and Sovereign Debt in the Euro Area
}

\author{
Deyan Radev* \\ Graduate School of Economics, Finance, and Management (GSEFM) \\ Johannes Gutenberg University Mainz
}

November 8, 2012

\begin{abstract}
We introduce a new measure of systemic risk, the change in the conditional joint probability of default, which assesses the effects of the interdependence in the financial system on the general default risk of sovereign debtors. We apply our measure to examine the fragility of the European financial system during the ongoing sovereign debt crisis. Our analysis documents an increase in systemic risk contributions in the euro area during the post-Lehman global recession and especially after the beginning of the euro area sovereign debt crisis. We also find a considerable potential for cascade effects from small to large euro area sovereigns. When we investigate the effect of sovereign default on the European Union banking system, we find that bigger banks, banks with riskier activities, with poor asset quality, and funding and liquidity constraints tend to be more vulnerable to a sovereign default. Surprisingly, an increase in leverage does not seem to influence systemic vulnerability.
\end{abstract}

Keywords: Sovereign debt, Sovereign default, Financial distress, Systemic risk, Contagion, Banking stability, Tail risk

JEL-Classification: C16, C61, G01, G21.

\footnotetext{
*I would like to thank Isabel Schnabel for valuable advice and support. This project was partially conducted while I was a guest reseracher at the Financial Stability Surveillance Division of the European Central Bank. I would like to thank Puriya Abbassi, Ivan Alves, Bernd Bartels, Andreas Barth, Frank Betz, Michael Binder, Carsten Detken, Paola Donati, Paul Hiebert, Denis Gorea, Charles Goodhart, Jan Pieter Krahnen, Melanie Krause, Silviu Oprica, David Schumacher, Ctirad Slawik and Constantin Weiser for valuable discussions and recommendations. This paper also benefited from the suggestions and comments of the ECB FSS staff and the participants of the 1st Workshop in Financial Economics, the Brown Bag seminar at Johannes Gutenberg University Mainz, the 2012 GSEFM Summer Institute and the 2012 Conferences of the German Economic Association and the German Finance Association. All remaining errors are my own.
} 


\section{Contents}

1 Introduction 1

2 Conditional Joint Probability of Default 3

2.1 Definition . . . . . . . . . . . . . . . . . . 3

2.2 Comparison with Other Measures . . . . . . . . . . . . . 6

2.3 Marginal Probability of Default . . . . . . . . . . . . . . . . . . 7

2.4 Multivariate Probability Density . . . . . . . . . . . . . . . . . 8

3 Euro Area Sovereign Default Risk $\quad 10$

3.1 Data and Descriptive Statistics . . . . . . . . . . . . . . . . 11

3.2 Marginal Probabilities of Default . . . . . . . . . . . . . . . . . 11

3.3 Conditional Joint Probabilities of Default . . . . . . . . . . . . . . . . . . . 12

3.4 Cascade Effects between Euro Area Sovereigns . . . . . . . . . . . . . . . . 14

4 Sovereign Default and the European Union Banking System 16

4.1 Bank Data . . . . . . . . . . . . . . . . . . 16

4.2 Empirical Strategy . . . . . . . . . . . . . . . . . . . . . 18

4.3 Spillover Effects from Sovereigns to Banks . . . . . . . . . . . . . . 18

5 Conclusion $\quad 20$

A Solutions and Proofs $\quad 25$

A.1 CDS Bootstrapping Procedure . . . . . . . . . . . . . 25

A.2 Consistent Information Multivariate Density Optimizing Approach . . . . . 26

A.3 Solution of Minimum Cross Entropy . . . . . . . . . . . . . . . . 28

A.4 Proof of Independence within the Default Region of the CIMDO Distribution 31

$\begin{array}{ll}\text { B Figures } & 34\end{array}$

$\begin{array}{ll}\text { C Tables } & 49\end{array}$ 


\section{Introduction}

One of the most pressing issues in current policy debates are the potential consequences of a sovereign default in the euro area. The answer to this question requires an accurate measurement of the feedback effects among sovereign debtors and between sovereigns and the banking system. This paper attempts to contribute to this discussion by providing a new measure of systemic risk that quantifies the effects of sovereign default risk on the financial stability of the eurozone.

This new measure of systemic risk, the change in the conditional joint probability of default $(\triangle C O J P O D)$, represents the contribution of the interdependence of an entity (a sovereign or a bank) with the financial system to the overall default risk of the system. ${ }^{1}$ We base our measure on probabilities of default, derived from CDS spreads. This allows us to capture the market perceptions about future systemic events in the debt market and to assess how they affect distress expectations in the financial system. In the subsequent empirical analysis, we use our measure to assess the systemic importance of EA sovereigns, cascade effects among the sovereigns, as well as spillover effect from EA sovereigns to the European Union (EU) banking system.

Our procedure to estimate systemic risk includes three steps. First, we derive individual probabilities of default from each entity's credit default swap (CDS) spread series, using a comprehensive procedure that follows Hull and White (2000). Second, since joint default risk is not traded, we need to impose some flexible structure on the interdependence between the individual entities under investigation. We apply the recently developed Consistent Information Multivariate Density Optimizing (CIMDO) methodology (Segoviano, 2006; Segoviano and Goodhart, 2009) to recover the euro area (EA) multivariate probability distribution. Third, we calculate the new systemic risk measure, the change in the Conditional Joint Probability of Default $(\triangle C o J P o D)$ using the derived multivariate density and investigate its properties.

Conceptually, our approach is related to the CoVaR (Adrian and Brunnermeier, 2010) and the Shapley value (Tarashev et al., 2010), which view systemic risk contributions as the difference in the value at risk (VaR) of the system when an entity defaults, compared to the case when no default occurs in the system. The main difference to those two concepts is that while they focus on conditional value at risk (the CoVaR) and conditional expected shortfall (the Shapley value), the objects of our analysis are conditional probabilities of default.

In concentrating on probabilities of default, our approach has several important advantages to the CoVaR and its related measures. First, the CoVaR relies on a restrictive definition of default: an institution is considered under distress if its returns drop in the

\footnotetext{
${ }^{1}$ Following Lehar (2005), Adrian and Brunnermeier (2010) and Tarashev et al. (2010), we assume that the financial system is a portfolio of European institutions - governments and banks.
} 
5-percent or the 1-percent region of its return distribution. In contrast, our approach does not take a stand on what a default actually means, but rather relies on the market expectations about the likelihood of a default to occur, based on an unobservable latent process. The main benefit of such an approach is that it allows us to derive systemic risk measures in a sovereign context without explicitly defining what sovereign assets are. Since the CoVaR relies exclusively on stock market data, and hence, on a very specific definition of an institution's asset distribution, it is not suitable to assess sovereign systemic risk.

A second major drawback of the CoVaR is that it uses historical stock market data. Giglio (2011) points out that reduced-form approaches, recovering return distributions from historical data, as the CoVaR, suffer from the low number of extreme events in market data. In contrast, our approach tries to circumvent this issue by recovering forwardlooking default probabilities from derivatives which are more sensitive to default risk, such as CDS contracts.

With respect to the estimation of sovereign default risk, relying on market perceptions about default, embedded in CDS premia, appears to be an attractive alternative to the Sovereign Contingent Claims Analysis of Gray, Merton and Bodie (2008) and Gray (2011). In these studies, the authors try to sort the capital structure of a sovereign in a particular way, depending on its maturity, in order to fit it to a Merton model's framework (Merton, 1974). This requires the assets and liabilities to be assigned to a category at every given point in time, making the method relatively cumbersome. Applying the CIMDO methodology, we avoid this procedure by focusing directly on probabilities of default derived from market data and assuming a standardized distribution for our initial beliefs about the individual entity's assets. Notwithstanding, we still rely on the intuition of the Merton model, that an entity (in our case - a bank or a sovereign) defaults on its debt, once its assets process crosses a certain default threshold.

Our results show that joint sovereign distress risk has increased since the end of 2009, parallel to a decoupling of investors' perceptions about individual sovereign default risk. We find that Germany and Netherlands have the highest individual contribution to the systemic risk of the euro area in case of default, while the effect of Greece is marginal at best.

With respect to the potential cascade effects among euro area, we concentrate on a particular scenario: we investigate how perceptions about a default of a relatively small EA sovereign (Portugal) affect default expectations of another small sovereign (Ireland), and how the expectations about their joint default affect the default perceptions about a larger sovereign (Spain). We find a high probability of distress spillover between the small sovereigns and between the latter and the large sovereign. This effect rises substantially after Lehman Brothers' bankruptcy and during the sovereign debt crisis. Therefore, we argue that possible default cascade effects of reasonable size should be taken into account 
in political decision-making.

Analyzing the effect of sovereign default on the EU banking system, we find that large banks are more vulnerable to sovereign risk, compared to medium-sized and small ones. This might indicate that these banks are considered by investors to be "too big to save" (Hellwig, 1998; Hüpkes, 2005; Demirgüç-Kunt and Huizinga, 2010; Völz and Wedow, 2011; Barth and Schnabel, 2012). With respect to financial gearing, we could not confirm a relationship between an increase in leverage and the default vulnerability. On the other hand, we find that higher-performing banks are expected to be more vulnerable to sovereign default, which might be explained with market perceptions that the higher returns are an indication of riskier activities. We also find that banks with poorer asset quality and banks that are funding- and liquidity-constrained tend to be considered as more vulnerable to sovereign default.

Hence, we contribute to the existing literature in four ways. First, we introduce a new and intuitive systemic risk measure that evaluates the contribution of the system's interdependence to systemic default risk. Second, we extend the relatively sparse literature on sovereign default in a multivariate setting by investigating not only the contribution of individual sovereigns to the systemic default risk, but also possible cascade effects within the euro area. Third, our study contributes to the financial stability literature that analyzes the feedback effects between sovereigns and the banking system (see, for instance, Demirgüç-Kunt and Huizinga, 2010, Barth and Schnabel, 2012, and Gorea and Radev, 2012). Fourth, at the methodological level, we are the first to analytically prove and among the first to explicitly address some of the limitations of the original CIMDO approach with regard to multivariate dependence. We also propose a procedure that alleviates the "curse of dimensionality" inherent in multivariate distribution modeling, based on sorting by banking financial characteristics.

The paper is organized as follows. In Section 2, we introduce the $\triangle C O J P o D$ measure and propose a procedure to derive it. Section 3 presents our results with regard to the systemic importance of euro area sovereigns. We also discuss the possible cascade effects among sovereigns. Section 4 explores how $\triangle$ CoJPoD could be applied to assess the spillover effects between euro area sovereigns and the European Union banking system. Section 5 concludes.

\section{Conditional Joint Probability of Default}

\subsection{Definition}

Our starting point in calculating our measure is to derive the joint probability of default $(J P o D)$ of the system, which can be interpreted as the system's fragility to default events. Let the system be described by a $n$-dimensional joint distribution, $P\left(x_{1}, x_{2}, \ldots, x_{n}\right)$, with 
density $p\left(x_{1}, x_{2}, \ldots, x_{n}\right)$, where $x_{1}, x_{2}, \ldots, x_{n}$ are the logarithmic assets of the respective institution $X_{1}, X_{2}, \ldots, X_{n}$.

Following Segoviano and Goodhart (2009), we then introduce the Joint Probability of Default $(J P o D)$ as:

$$
J P_{O} D_{x_{1}, x_{2}, \ldots, x_{n}}=J P_{O} D_{\text {system }}=\int_{\overline{\mathbf{x}}_{1}}^{+\infty} \int_{\overline{\mathbf{x}}_{2}}^{+\infty} \ldots \int_{\overline{\mathbf{x}}_{n}}^{+\infty} p\left(x_{1}, x_{2}, \ldots, x_{n}\right) d x_{1}, d x_{2} \ldots d x_{n}
$$

where $\overline{\mathbf{x}}_{1}, \overline{\mathbf{x}}_{2}, \ldots, \overline{\mathbf{x}}_{n}$ are the individual default thresholds ${ }^{2}$ of the respective entities. ${ }^{3}$

Then, applying Bayes rule, we derive the Conditional Joint Probability of Default of the system of $n$ entities, conditional on entity $k$ defaulting:

$$
\begin{aligned}
\operatorname{CoJPoD}_{\text {system }_{-k} \mid x_{k}>\overline{\mathbf{x}}_{k}} & =J P o D_{x_{1}, x_{2}, \ldots, x_{k-1}, x_{k+1}, \ldots, x_{n} \mid x_{k}>\overline{\mathbf{x}}_{k}} \\
& =\frac{J P o D_{x_{1}, x_{2}, \ldots, x_{n}}}{\operatorname{PoD}^{k}} \\
& =\frac{J P o D_{\text {system }}}{P o D^{k}}
\end{aligned}
$$

where $P o D^{k}$ is the individual default probability of entity $k$. Therefore, the conditional probability of default is a ratio between the general vulnerability of the system and the individual default vulnerability.

Note that, by definition, Bayes rule gives us the conditional probability of the remaining (non-defaulting) entities in the system. It does not, however, tell us what their probability would have been without the shock due to entity $k$ 's default. What we would like to compare the conditional probability of the surviving entities with, is their unconditional probability, which might also be considered as their general vulnerability during "tranquil" times. Therefore, to calculate the contribution of entity $k$ 's default on system's default risk, we subtract from $C_{O} J P_{O} D_{\text {system }_{-k} \mid x_{k}>\overline{\mathbf{x}}_{k}}$ the unconditional JPoD of the system constituents excluding the entity in question. Our $\triangle$ CoJPoD measure is then

$$
\Delta \operatorname{CoJPoD} \text { system }_{-k} \mid x_{k}>\overline{\mathbf{x}}_{k}=\operatorname{CoJPoD} \text { system }_{-k} \mid x_{k}>\overline{\mathbf{x}}_{k}-J P o D_{\text {system }} .
$$

In essence, we compare the risk of the system when entity $k$ is included and defaults, to the situation where entity $k$ is excluded, or otherwise said - independent from the system. So defined, $\triangle C O J P O D$ is the probabilistic alternative to the CoVaR (Adrian and Brunnermeier, 2010).

Next, we define $J P o D_{\text {system }}^{\prime}$ as the joint probability of default of the system if entity

\footnotetext{
${ }^{2}$ The default thresholds are defined in the sense of the classical structural model by Merton (1974).

${ }^{3}$ Note that, as in Segoviano (2006) and Segoviano and Goodhart (2009), our default region is in the right tail of the distribution. This does not affect our results, but simplifies our estimation procedure.
} 
$k$ is independent of the rest of the system, other things equal. Therefore, the prime indicates that the only difference between $J P o D_{\text {system }}$ and $J P_{o} D_{\text {system }}^{\prime}$ is that in $J P o D_{\text {system }}^{\prime}$ we assume independence between entity $k$ and every other entity in the system. Both probability measures are identical in any other aspect of their underlying dependence structure. Applying Bayes rule, we can reformulate $J P_{o} D_{\text {system }}^{\prime}$ as

$$
\begin{aligned}
J P_{O} D_{\text {system }}^{\prime} & =J P O D_{x_{1}, x_{2}, \ldots, x_{k-1}, x_{k}, x_{k+1}, \ldots, x_{n}}^{\prime} \\
& =J P O D_{x_{1}, x_{2}, \ldots, x_{k-1}, x_{k+1}, \ldots, x_{n} \mid x_{k}>\overline{\mathbf{x}}_{k}}^{\prime} \cdot P o D^{k} \\
& =J P O D_{x_{1}, x_{2}, \ldots, x_{k-1}, x_{k+1}, \ldots, x_{n}}^{\prime} \cdot P o D^{k} \\
& =J P O D_{\text {system }_{-k}} \cdot P o D^{k}
\end{aligned}
$$

Then, $J P o D_{\text {system }_{-k}}$ can also be represented in the following way:

$$
\begin{aligned}
J P_{O} D_{\text {system }_{-k}} & =\frac{J P o D_{x_{1}, x_{2}, \ldots, x_{n}}^{\prime}}{\operatorname{PoD}^{k}} \\
& =\operatorname{CoJPoD}_{\text {system }_{-k} \mid x_{k}>\overline{\mathbf{x}}_{k}}^{\prime},
\end{aligned}
$$

where $C o J P o D_{\text {system }}^{\prime} \mid x_{k}>\overline{\mathbf{x}}_{k}$ is the conditional counterpart of $J P o D_{\text {system }}^{\prime}$ with respect to entity $k$. Thus, our systemic risk contribution from equation $3, \Delta C_{o} J P o D_{\text {system }_{-k} \mid x_{k}>\overline{\mathbf{x}}_{k}}$, transforms to

$$
\Delta \operatorname{CoJPoD}_{\text {system }_{-k} \mid x_{k}>\overline{\mathbf{x}}_{k}}=\operatorname{CoJPoD} \text { system }_{-k} \mid x_{k}>\overline{\mathbf{x}}_{k}-\operatorname{CoJPoD}_{\text {system }_{-k} \mid x_{k}>\overline{\mathbf{x}}_{k}}^{\prime} .
$$

The measure can be viewed hence as the difference between the effects of default on systemic fragility when the system is dependent or independent of the respective entity. Thus, $\triangle C_{O} J P_{O} D_{\text {system }_{-k}} \mid x_{k}>\overline{\mathbf{x}}_{k}$ measures the contribution to the systemic default risk due to the system's interdependence with entity $k$.

We should note that in our approach interdependence does not mean interconnection. Sovereigns with no or minor direct financial and trade linkages could still be interdependent if the markets perceive them to be similar in any way. This perceived similarity causes a comovement of their individual CDS series, which reflects a comovement of the market perceptions about the default of the individual sovereigns. Therefore, analogously to the CoVaR, our measure does not reflect a causal relationship. Nevertheless, we could witness a directionality in our conditional indicator: the CoJPoD of sovereign A defaulting given that sovereign $\mathrm{B}$ defaults could be different from the CoJPoD of sovereign $\mathrm{B}$ defaulting given sovereign A defaults.

There are numerous ways to calculate the individual and joint probabilities of default to derive $\triangle C O J P_{o} D_{\text {system }_{-k} \mid x_{k}}$. To calculate individual probabilities of default (PoD), 
we choose a bootstrapping procedure that incorporates all available CDS contracts of an entity up to a 5-year horizon. Then we transform the individual PoDs into multivariate PoDs using the CIMDO procedure introduced by Segoviano (2006).

\subsection{Comparison with Other Measures}

Since the $\triangle C O J P_{O} D$ is a measure of default risk contributions, the first candidate for a comparison is the CoVaR (Adrian and Brunnermeier, 2010). Gramlich and Oet (2011) outline several properties that a successful systemic risk measure should possess: consistency, flexibility, forward-looking focus, correspondence with empirical data, suitability for the need of financial regulators. In that respect, as mentioned earlier, the CoVaR suffers from the limited number of extreme returns in market data, which precludes it from a consistent forward-looking estimation of systemic risk. As we base our measure on CDS data, it is exclusively forward-looking and is consistent with the default expectations of market participants within a 5-year horizon. Another limitation of the CoVaR is that it is unable to tackle multivariate interactions, as it models either interactions between two institutions, or between an institution and an aggregated index of the financial system. Therefore, it neglects the underlying dependence between the institutions in the system's "portfolio". In contrast, in our approach we employ a "true" multivariate setting for our $\triangle C o J P o D$-measure by explicitly modeling the dependence structure among all entities in the system. Furthermore, our empirical applications in the next subsections will show how flexible the measure is in capturing not only individual default contributions, but also cascade effects conditioning on a default of several countries, and sovereign default spillover effects to the banking system.

With respect to multivariate default probability estimation, the financial stability literature puts an emphasis mainly on measuring banking distress risk (see, for example, Lehar, 2005, Avesani et al., 2006, Segoviano and Goodhart, 2009, and Giglio, 2011). Of particular interest to supervisors is the probability of at least two banks defaulting (see Avesani et al., 2006, and Radev, 2012, for two approaches to derive this measure). Gorea and Radev (2012), Radev (2012) and Zhang et al. (2012) propose procedures to calculate these measures in a sovereign context. The latter application is rarely explored in the literature, due to the different nature of sovereign and corporate assets. The aforementioned authors do not try to define what sovereign assets are (contrary to the approach of, for instance, Gray, 2011), but rather rely on the judgement of market participants about the probability of a latent sovereign assets process to cross a given sovereign default threshold. The latter probability is derived from CDS spreads. Such a general view allows researchers to extend the definition of sovereign assets to anything that would affect a government's decision to default, be it public revenues or willingness to pay. Furthermore, the focus on market perceptions about sovereign default risk has important implications for regulators 
during the current sovereign debt crisis, as euro area governments rely predominantly on the international financial markets to finance their liquidity needs.

Most of the proposed probability measures in the cited studies are unconditional by definition and when authors derive conditional measures, they do not compare them to counterfactual events. A notable exception is the "spillover component" or "contagion effect" measure, derived by Zhang et al. (2012). In contrast to the approach underlying the $\triangle$ CoJPoD, however, the authors choose to take the difference between the conditional probability of default of a sovereign (Portugal in their case), given another sovereign (Greece) defaults and the conditional probability given the latter does not default. The latter term is the authors' definition of the "tranquil" state of the world. The authors keep the same dependence structure in both components of their measure, which precludes them to interpret it as a contribution to systemic default risk due to interdependence.

\subsection{Marginal Probability of Default}

A common method for estimating probabilities of default from CDS spreads is to use the most liquid contracts in the market, 5-year CDS spreads, to estimate one-year probabilities of default, applying the simple formula

$$
\operatorname{PoD}_{t}=\frac{C D S_{t} * 0.0001}{1-\text { Recovery Rate }},
$$

where $C D S_{t}$ is the 5 -year CDS spread at time $t, P_{o} D_{t}$ is the resulting probability of default estimate and Recovery Rate is an assumed recovery rate of the face value of the underlying bond in case of default.

We use a refined way of estimating probabilities of default (PoD), the CDS bootstrapping, outlined in Appendix A.1. The procedure follows Hull and White (2000) and is based on a simple cumulative probability model, which incorporates recovery rates, refinancing rates and cumulative compounding. The model uses CDS contracts of different maturities to calibrate hazard rates of particular time horizons in order to estimate cumulative probabilities of default. This method can be used for both sovereign and corporate probability of default estimation. The resulting risk measures are risk-neutral probabilities of default and satisfy the no-arbitrage condition in financial markets.

We propose using all available maturities from 1 to 5 years of CDS spreads to derive the PoD of an entity. The CDS contracts have quarterly premium payments as a general rule, so we adjust the procedure accordingly. We also correct for accrual interest, as suggested by Adelson et al. (2004). As refinancing rates, required as inputs, we use all available maturities of AAA Euro Area bond yields from 1 to 5 years. The recovery rate is uniformly set at $40 \%$, both for banks and sovereigns, as this is the prevailing assumption in the literature and in practice. ${ }^{4}$ The resulting series are 5-year cumulative probabilities

\footnotetext{
4 Sturzenegger and Zettelmeyer (2005) find that the historical sovereign recovery rates are usually
} 
of default, which we annualize in order to accommodate the one-year horizon of interest to policy makers, using the formula:

$$
\text { PoD } D_{t}^{\text {annual }}=1-\left(1-\text { PoD }_{t}^{\text {cum }}\right)^{\frac{1}{T}},
$$

where $T$ is the respective time horizon ( $\mathrm{T}=5$ for 5 -year $\mathrm{PoD})$ and $P o D_{t}^{\text {annual }}$ is the annualized version of the cumulative $P o D_{t}^{\text {cum }}$.

Figure 1 presents the results from the naïve and the bootstrapping procedures for a distressed sovereign, namely Greece, for the period 01.01.2008 to 31.12.2011. We notice the main drawback of the simple calculation method. While the series generally overlap in tranquil times, they diverge during the distress period starting from May 2010. The margin increases rapidly with the rise of CDS spreads, leading to results higher than unity at the end of the period, which we truncate at 1 to match the definition of probability. The bootstrapped probabilities, on the other hand, have fairly reasonable annualized values in the distress period, peaking in the region from 45 to $50 \%$. The reason for this misalignment is that the naïve Formula 7 can be seen as a linear approximation of the more elaborate bootstrapping procedure, and does not account for all its caveats. The formula performs well for entities with low levels of CDS spreads (Germany, France, Deutsche Bank), but fails for distressed sovereigns or corporates (Greece, Dexia).

It can be argued that the risk neutral probabilities recovered from market CDS data are downward-biased because of the euro area sovereign bailout packages and the government guarantees for the banking sector. Therefore, we can interpret the individual probabilities of default in our analysis (as well as the joint probabilities based on them) as lower bounds for the risk neutral probabilities in case when no bailout guarantee is available.

\subsection{Multivariate Probability Density}

Since joint credit events are rarely traded in the default insurance market, we need to impose a certain structure on the system's joint probability density, in order to transform individual to joint probabilities of default. Our structure of choice is the CIMDO distribution, a result of the CIMDO methodology introduced by Segoviano (2006). This methodology builds on the minimum cross-entropy procedure by Kullback (1959) and consists in recovering an unknown multivariate asset distribution using empirical information about its constituting marginal distributions. As Segoviano and Goodhart (2009) point out, the

between 30 and 70\%. Zhang et al. (2012) use those results as motivation to choose $50 \%$ recovery rate for their default estimations. We decide to be more conservative with regard to the loss given default assumption, as the recent negotiations for the Private Sector Involvement (PSI) in the Greek bailout packages suggest haircuts between 50 and $70 \%$. As non-institutional investors are the main participants in the CDS markets, we argue that their expectations of default risk are what the CDS spreads reflect, thus we remain with the usual recovery rate convention in financial literature. For a discussion on how different recovery rates affect the PoD estimates, please refer to the robustness checks section in Gorea and Radev (2012). 
CIMDO approach is related to the structural credit model by Merton (1974), where an entity defaults if its asset value crosses a predefined default threshold. The difference of the CIMDO model to the structural model comes from the fact, that in the former the threshold is fixed, while in the latter, it is allowed to vary. With the default threshold fixed, the CIMDO approach changes the probability mass in the tails of an ex ante (or prior) joint asset distribution according to the market expectations about the probability of default of each individual entity. The subsequent posterior joint distribution, or CIMDO distribution, has two main properties: first, it reflects the market consensus views about the default region of the unobserved asset distribution of the system, and second, it possesses fat tails, even if our starting assumption is joint normality. The latter property reflects the well-documented fact that financial markets are characterized by a higher number of crashes than predicted by the normal distribution. Furthermore, regardless of the ex ante joint distribution assumption (a joint normal or a fatter-tailed distribution) the posterior CIMDO distribution is consistent with the observed data.

Put in perspective, the CIMDO methodology has the advantage over many Mertonbased methods, most prominently the Contingent Claims Analysis (CCA) by Gray, Merton and Bodie (2008) and the approach of Lehar (2005), due to its departure from normality and the intrinsically dynamic dependence structure, represented by the CIMDO copula. The CIMDO approach has also been shown to perform exceptionally well in the default region of the system's joint distribution, compared to standard and mixture distributions that are usually used to model market comovement. ${ }^{5}$

Segoviano (2006) and Gorea and Radev (2012) and Radev (2012) analyze the robustness of the CIMDO approach with respect to some of its main underlying parameters: prior distribution and dependence structure assumptions, turning special attention to the performance in the default region of the posterior joint distribution. Their results show that assuming a multivariate standard normal distribution as a prior provides very similar results to employing a fatter-tail distribution. The resulting posterior distribution is sufficient to explain the behavior in the default region of the distribution of sovereign assets and assuming a more complex prior distribution does not provide a significant improvement. Therefore, we decide to use a multivariate joint normal distribution for our prior, as in the original work by Segoviano (2006). We provide a formal definition of the CIMDO approach in Appendix A.2, as well as a solution of the minimum cross entropy procedure in Appendix A.3.

A commonly overlooked property of the CIMDO model is that if independence is assumed for the prior distribution (e.g. by assuming a zero-correlation structure for the prior distribution, as in Segoviano, 2006), ${ }^{6}$ this transfers to the posterior distribution

\footnotetext{
${ }^{5}$ See Segoviano (2006) and Segoviano and Goodhart (2009) for further information and discussions.

${ }^{6}$ In general, zero correlation does not imply independence and simple analytical examples are readily available. However, if zero correlation is assumed for a joint normal asset distribution, the resulting joint probabilities of default are a product of the individual entity probabilities of default. Hence, any systemic
} 
as well. Appendix A.4 provides a multivariate proof of this caveat when multivariate joint normal distribution is assumed as a prior. In a recent study, Peña and RodriguezMoreno (2010) compare the predictions of several systemic risk models, including the CIMDO-derived Banking Stability Index (BSI), but assume zero-correlation structure for the CIMDO's initial distribution. If this assumption proves wrong, which most likely is the case for the bank assets investigated in the mentioned study, that would lead to significant underestimation of the joint default risk between the considered entities. Even more, due to the independence of the posterior distribution, any conditional measures derived using it will be identical to their unconditional counterparts. The latter fact has a huge effect on our $\triangle C O J P_{O} D$ measure, as it is exactly the difference between the conditional JPoD and its unconditional alternative. It can be shown that this measure will be exactly 0 at any point of time, despite any dynamics in the individual PoDs. Empirical evidence for this analytical result is provided in Section 3.3.

Since the initial correlation structure assumption is crucial for the CIMDO approach, we rely on market estimates to explicitly allow it to differ from the identity matrix. The distress correlation structure is proxied by the empirical correlation between changes in the 5-year CDS spreads of the sovereigns and banks in our sample.

\section{Euro Area Sovereign Default Risk}

Our empirical analysis is organized as follows. First, we investigate the default risk contributions among 10 euro area sovereigns. With the sovereign debt crisis at its peak, it is important to analyze the dynamics of our systemic risk measure and identify possible trends, as well as major regulatory interventions and their effects. Second, we focus on the influence of sovereign default risk on the European banking system. We select both euro area and non-euro area EU banks for our analysis, as recent events have shown that the high interconnectedness of the EU banking system facilitates spillover effects from the distressed euro area sovereigns. The empirical financial stability literature that concentrates on CDS markets usually incorporates a very limited number of European banks. Therefore, our set of thirty six banks makes the current analysis a representative study of the systemic fragility of the European Union banking system.

probability measure that conditions on particular entities defaulting, will be equal to the product of the PoDs of the remaining entities. Otherwise said, the conditioning on some entity defaulting, we do not get additional information about the default of the remaining entities, apart from the one already contained in their individual probabilities of default. The latter fact exactly complies with the probabilistic definition of independence. 


\subsection{Data and Descriptive Statistics}

We estimate marginal probabilities of default using CDS premia for contracts with maturities from 1 to 5 years for the period 01.01.2008 and 31.12.2011. The employed procedure (for details, see Hull and White, 2000, Gorea and Radev, 2012, and Appendix A.1) requires as additional inputs refinancing interest rates, which we choose to be the AAA euro area government bond yields for maturities from 1 to 5 years. The CDS spreads and the government bond yields are at daily frequency, which is also the frequency of the resulting probabilities of default. Our analysis covers 10 euro area (EA) sovereigns (Austria, Belgium, France, Germany, Greece, Ireland, Italy, Netherlands, Portugal and Spain). For consistency, the CDS contracts are denominated in euro. ${ }^{7}$ The source for the sovereign CDS spreads and the government bond yields is Datastream, while the exchange rate quotes are downloaded from Bloomberg.

Table 1 presents the descriptive statistics of the 5-year CDS spreads of the ten countries in our sample. The average 5-year CDS spread in the cross-section ranges from 29 basis points for Germany to 774 basis points for Greece. We can also notice a substantial increase of CDS premia even for the safest country, Germany, from 3 to 91 basis points. However, this cannot be compared with the dynamics of the price for protection against the default of Greece, which starts from 15 basis points in the beginning of the period and reaches 11034 basis points on December 16, 2011. We also see that the safest countries, Germany and Netherlands, have the lowest volatility of the price for protection against default.

\subsection{Marginal Probabilities of Default}

Figure 2 depicts the CDS-implied annualized probabilities of default for the 10 euro area sovereigns in our analysis. We observe very similar values in the beginning of our sample period, pointing towards investors' confidence in the individual EA members' ability to service their debt. We observe a peak in the individual PoDs during the global recession after Lehman Brother's collapse, but the individual default risk gradually falls throughout 2009. A major decoupling occurs in November 2009, after the announcement of the newly-elected Greek government that the previously reported data on the government deficit was strongly misleading. The following divergence of market expectations

\footnotetext{
${ }^{7}$ In order to arrive at compareable CDS-derived probabilities of default, all components in the calculation should be under a common currency measure. For many of the sovereigns both euro and US-dollar-denominated CDS contracts are traded. In an unreported analysis, we came to the conclusion that the difference in the absolute levels of the series cannot be explained solely by the exchange rate dynamics. As CDS contracts are usually traded over the counter, it is difficult to find information on the exact volumes traded of each type. After additional talks with professionals, we were assured that in the case of sovereigns, the US-dollar-denominated contracts are more liquid. For this reason, when available, those were chosen in our analysis and the data was transformed using euro-dollar exchange rates, downloaded from Bloomberg.
} 
about individual sovereign default risk might be due not only to doubts in the individual governments ability to service their debt, but also in the potential of the euro area as a whole to support its members in need. We also notice that the PoD level of Greece rises throughout the whole period, while the default risk perceptions with regard to the remaining distressed countries - Ireland, Italy, Portugal and Spain - seem to stabilize in the second half of 2011.

\subsection{Conditional Joint Probabilities of Default}

In this section, we present the $\triangle C O J P o D$ results for our set of euro area sovereigns. ${ }^{8}$ Let us first investigate the ingredients of the $\triangle C_{O} J P_{O} D$ measure. Figure 3 shows the results for the correction term $J P o D_{\text {system }_{-k}}$ in Equation 3. The general vulnerability of the reduced system rises throughout the period and reaches $0.25 \%$ by the end of 2011 . What might seem surprising at first glance, is that excluding Greece apparently increases the vulnerability of the rest of the system. This result can be explained after a closer examination of Table 2. Due to the already mentioned decoupling in investors' perceptions about individual sovereign risk, especially with regard to Greece, Greek assets seem to be less correlated with the rest of the system. Hence, if Greece is included in $J P o D_{\text {system }}$ (all 9 cases where Greece is not the entity $k$ ), and another, more highly correlated sovereign, is excluded (that is - assumed to be independent from the rest of the system), this intuitively reduces the $J P_{O} D_{\text {system }_{-k}}$. And conversely, if Greece is the particular entity $k$, the correlation between the remaining entities in system $_{-k}$ is higher, leading to a higher probability of them to jointly default (purple line).

Figure 4 provides the results for the conditional joint probability of default of the system, given a particular sovereign defaults. We notice that the ordering is now inverted, compared to the individual PoDs depiction. The highest CoJPoD is in the case of a default of Germany, narrowly traced by that of Netherlands. This is intuitive, since those countries are perceived to be the safest in the euro area system. Therefore, their default should have a significant effect on the perceptions about the default risk of the remaining, riskier countries.

In Figure 5, we present the $\triangle C O J P o D$ results for the 10 euro area sovereigns. As expected from the analysis of CoJPoD, Germany and Netherlands have the highest perceived contribution to the euro area default risk, given their own default. We observe that before Lehman Brothers' bankruptcy in September 2008 the perceptions of the systemic risk contribution of a country's default were practically non-existent. This derives directly from the fact that a joint sovereign default within the euro area was perceived as a highly unlikely event. The contribution rises during the turmoil period after Lehman's default, and peeks between January and April 2009, gradually subsiding afterwards. The

\footnotetext{
${ }^{8}$ In Table 2, we report the dependence structure that we employ in our euro area sovereign analysis.
} 
$\triangle C O J P o D$ measure starts rising again after the announcement of the Greek government budget problems in November 2009 and peeking at nearly 10 percentage points for Germany at the end of November 2011.

A more elaborate interpretation of the $\triangle C o J P o D$ is that its first part, the CoJPoD, reflects the relative dynamics of systemic fragility $\left(J P o D_{\text {system }}\right)$ and the individual default risk of a sovereign $\left(P o D_{k}\right)$. For the case of Germany, although its individual risk has been increasing slightly but steadily throughout the sample period, systemic fragility obviously has risen with faster (or fallen with slower) pace. At the other end of the spectrum is Greece, where the individual risk dynamics have outpaced those of the system, both in terms of growth and in magnitude, resulting in a lower risk contribution due to interdependence. A positive result for the risk contribution $\triangle C o J P o D$ means that, due to the interconnectedness of the respective sovereign to the rest of the euro area, the fragility of the system rises by more than if the country default is an independent event. Overall, the results for $\triangle C O J P_{O} D$ mean that for Germany this difference is much higher than the respective effect of a default of any other country.

The reader should notice that there is a second effect contributing to the final results, apart from pure dependence, namely the level effect of the systemic and individual default risks. As the individual level of default risk of Greece is high compared to the systemic default risk level, CoJPoD will be low, leading to low results for $\triangle C o J P o D$, as well. The benefit of our model is that it takes into account the interaction of both effects when evaluating the effects of interdependence on systemic default risk.

Comparing the results for CoJPoD and $\triangle$ CoJPoD, we do not see large differences, especially for Germany and Netherlands. This stems from the relatively low magnitude of the unconditional adjustment term $J P o D_{\text {system }_{-k}}$ for those countries. The lower is CoJPoD, the higher the relative contribution of the adjustment term to $\triangle C O J P o D$. We can see this in the results for Greece, where, after the adjustment, the relative contribution to the systemic default risk is practically wiped out. We can relate this fact to our observation that $J P o D_{\text {system }_{-k}}$ for Greece is higher than for any other country, due to its low correlation with the rest of the system.

The effects of low correlation are taken to their extreme in Figure 6, where we present the results for $\triangle$ CoJPoD if the countries are assumed to be independent. As argued in Section 2.4, the default contribution of any of the sovereigns is not different from 0 , due to the fact that under independence, the conditional and unconditional JPoD are the same. This analysis shows that if we assume that sovereigns are independent, ${ }^{9}$ this will lead to misleadingly low contributions to systemic risk.

\footnotetext{
${ }^{9} \mathrm{An}$ example for such an assumption in a CIMDO-related context can be seen in Peña and RodriguezMoreno (2010).
} 


\subsection{Cascade Effects between Euro Area Sovereigns}

When analyzing contagion in the financial system, one has to take into account its spacial dimension: a default event for a particular sovereign might affect perceptions about the default of another one and their potential joint default might spread to others, in many cases safer sovereign borrowers, and ultimately affect the default expectations with regard to the whole sovereign financial system. In this section, we show how the $\triangle C o J P o D$ could be used to investigate such "cascade" effects by considering a particular path through which a default of one sovereign might spread through the system.

We start by examining the change in the conditional probability of default of Ireland, given Portugal defaults. With a minor abuse of notation for the sake of parsimony, the general $\triangle$ CoJPoD definition in Equation 3 transforms to:

$$
\triangle C o J P o D_{I r \mid P t}=C o J P o D_{I r \mid P t}-P o D_{I r},
$$

where CoJPoD $I r \mid P t$ is the conditional probability of default of Ireland (Ir) given the assets of Portugal (Pt) cross its default threshold and $P_{O} D_{I r}$ is the marginal (empirical) probability of default of Ireland. Compared to Equation 3, the counterfactual joint probability of default of the surviving entities in the system narrows down to a single dimension.

In Figure 7, we present the results for each of the components on the right-hand side of Equation 9. We witness a significant gap between the conditional probability of Ireland defaulting given Portugal defaults (blue) and its unconditional counterpart (red). Obviously, observing the individual probabilities of default, or even the raw individual CDS data, does not provide a comprehensive perspective of the complex interactions underlying investors' perceptions about sovereign default.

Figure 8 displays the dynamics of $\triangle C_{O} J P_{O} D_{I r \mid P t}$. We observe that the contribution of a Portuguese default to the distress vulnerability of Ireland rises from relatively modest 10 percentage points to almost 60 percentage points at the peak of the global recession after Lehman Brothers' bankruptcy. Although our measure falls subsequently, it hardly drops below 30 percentage points. We document a new rise from the beginning of 2010 on, reaching 50 percentage points in early 2011. The contribution slowly declines thereafter and stabilizes around 40 percentage points by the end of 2012. Overall, we find a strong effect of a potential Portuguese default on the default expectations about Ireland.

The results from Figure 8 show that, as far as market perceptions are concerned, a default of Portugal is expected to substantially affect the default likelihood of Ireland. Yet, since both countries are relatively small, their difficulties could be fully addressed by the financial stabilization facilities, organized to prevent the spread of the sovereign debt crisis. ${ }^{10}$ A recurring theme in the debates between policymakers and regulators is whether

\footnotetext{
${ }^{10}$ The European Financial Stability Facility (EFSF) and the European Financial Stabilization Mechanism (EFSM) were introduced in May 2010 with an initial mandate to borrow up to 500 billion euro
} 
a default of these smaller sovereigns could spread to the bigger EA periphery economies, that is, to Spain and Italy. ${ }^{11}$ The amount of public debt of these two countries exceeds the size of the aforementioned funding facilities. Therefore, as a next step, we investigate how the joint default of Ireland and Portugal could affect the default perceptions with regard to Spain. To address this issue, we reformulate our Equation 3 to take the following form:

$$
\triangle C_{o J} P_{o} D_{S p \mid I r, P t}=C_{o J P} P_{S p \mid I r, P t}-P_{o} D_{S p},
$$

with $C o J P_{o} D_{S p \mid I r, P t}$ being the probability of Spain defaulting, given Ireland and Portugal default.

The results for $\triangle C O J P_{0} D_{S p \mid I r, P t}$ are presented in Figure 9. Although the time series is less volatile, we observe similar level and time paths of default risk contribution to those in Figure 8. The peak is in mid-2010 (55 percentage points), followed by a gradual reduction of the perceived default risk contribution up until July 2011 when the contribution rises again, stabilizing at the relatively high level of 40 percentage points. Therefore, we find that a joint default of Ireland and Portugal substantially increases the perceived default risk of Spain.

The final step of our cascade effects analysis is an examination of how a default of all three entities affects the perceived default vulnerability of the EA system. This leads to the following $\triangle$ CoJPoD definition:

$$
\Delta C o J P o D_{\text {system-Sp,Ir,Pt|Sp,Ir,Pt }}=C o J P o D_{\text {system-Sp,Ir,Pt|Sp,Ir,Pt }}-J P_{o} D_{\text {system-Sp,Ir,Pt }},
$$

where CoJPoD $D_{\text {system-Sp,Ir,Pt|Sp,Ir,Pt }}$ is the perceived probability of default of the surviving EA sovereigns, given a joint default of Spain, Ireland and Portugal.

In Figure 10, we present the results for $\triangle C o J P o D_{\text {system-Sp,Ir,Pt|Sp,Ir,Pt }}$ in the sample period (blue), compared to the respective $\triangle C O J P o D$ results when only Spain defaults in the EA system taken from Figure 5 (red). We notice that the systemic default risk contribution triples during the post-Lehman global recession and doubles during the current sovereign debt crisis, compared to the case of a standalone default of Spain. Therefore, we argue that possible default cascade effects of reasonable size should be taken into account in policy decision-making.

to maintain the financial stability of the eurozone. Additional 250 billion euro could be borrowed by the International Monetary Fund within this initial agreement. As of December 2011, the sizes of public debt of Ireland and Portugal are 169 billion euro and 184 billion euro, respectively (Eurostat, 2012).

${ }^{11}$ Digressing to the general financial stability literature, Zhou (2010) points out that when assessing the systemic role of a financial institution, we should consider whether its distress co-occurs with distress of other institutions - the so called "too-many-to-fail" problem, investigated by Acharya and Yorulmazer (2007). Zhou (2010) argues that this effect is more relevant for financial crises than the popular "toobig-to-fail" argument. 


\section{Sovereign Default and the European Union Bank- ing System}

In this section, we shift the focus of our investigation from the pure sovereign debt perspective and study the perceived effects of sovereign default on the EU banking system. The topic of whether and how a sovereign default could affect the EU financial system is of major concern for regulators, as EU banks hold most of the debt generated by euro area countries and this debt is a sizable part of the banks' assets portfolios.

\subsection{Bank Data}

In the analysis of spillover effects of sovereign default to the banking system, we use 36 European Union (EU) banks, out of which 28 are euro area banks. The lists of banks in our analysis are presented in Tables 3 and 4. The sources of the CDS data are Datastream and Bloomberg.

To reduce the effect of the curse of dimensionality, we choose to form equal-size portfolios within our banking sample. The latter construction choice makes our results comparable across portfolios. The allocation of each bank in a portfolio is governed by the position of the bank in the distribution of a set of financial characteristics. We select ten financial statement indicators, singled out in the financial literature as important systemic risk factors. ${ }^{12}$ Those factors form five broad groups: size, financial gearing, asset quality, performance, and liquidity and funding.

Size. We measure the bank's size by the amount of its total assets (TA). Brunnermeier and Pedersen (2009) identify size as a major driver of systemic risk, according to their theory of the "margin spiral." The authors provide evidence that banks adjust their assets, such that leverage is high in upturns and low in downturns of the economic cycle, making leverage a procyclical characteristic. Sorting by size should provide us with insights whether bigger banks were exposed to higher default risk stemming from sovereign difficulties in the indicated period.

Leverage. Adrian and Brunnermeier (2010) propose the assets-to-equity (AE) ratio as a measure of financial gearing. The intuition behind this sorting is that banks with higher leverage should be more susceptible to adverse credit events in the financial markets. Moreover, many large European Union banks invested heavily in EA sovereign bonds before and during the sovereign debt crisis (EBA, 2011; IMF, 2011) and could become insolvent in case of a sudden drop in the value of their assets.

Asset quality. We use two measures for asset quality. The first one is the ratio of loan loss provisions to net interest income. This indicator reflects whether the lending

\footnotetext{
${ }^{12}$ The raw data for the individual bank characteristics for the analyzed period are provided by Bloomberg and Bankscope.
} 
risk undertaken by the banks is appropriately remunerated by higher interest margins. Hence, this measure should be as low as possible. Our second measure for the quality of a bank's portfolio of assets is the ratio of non performing loans to total loans and is sometimes referred to in practice as the "doubtful loans" (DL) ratio. An increase in this measure should make banks more vulnerable to credit events that further impair their loan quality.

Performance. We use four indicators to measure a bank's performance. The first indicators is the return on equity (ROE), which is a standard measure of corporate efficiency. The main benefit of this measure is that it shows the profitability of the funds invested or reinvested in the company's equity. The main drawback comes from the fact that high-leverage companies could have artificially high ROE ratios, which might reflect the company's excessive risk-taking, rather than its growth potential. The second indicator is the return on assets (ROA), which is the profit from every euro of assets that the bank controls. A potential weakness of this accounting measure is that the balance sheet value of assets may differ from the market value of assets, making it difficult to draw comparisons across industries. Within the banking industry this is less of an issue, due to the relatively regular marking to market of assets. Our third measure is the net interest margin (NIM). The NIM is calculated as interest income minus interest expenses over average earning assets. It indicates how successful the bank's investment decisions were in comparison to the interest-bearing assets. A negative value could indicate a non-optimal banking credit policy or a fast deterioration in the quality of assets. Our last measure is the bank's efficiency ratio (ER). This ratio compares the overhead costs of running the bank to the revenues from the bank's business. The higher the ratio, the less efficient the bank's operations are.

Liquidity and Funding. Our last category includes two indicators. The first one is the deposits-to-funding (DF) ratio, which is calculated by dividing total deposits by total funding (sum of total deposits, short- and long-term borrowing and repurchase agreements). This measure reflects the share of stable funding (deposits) to the total amount of a bank's funding. The less a bank relies on wholesale funding, the less exposed it is to global volatility and credit crunches during global crises. The higher this ratio, the better protected is a bank against global market fluctuations. ${ }^{13}$ The second liquidity measure is net loans to total assets. This liquidity indicator reflects the share of loans less loan loss provisions to total assets. An increase in that ratio may signal liquidity shortages, as the company has an increasing proportion of illiquid assets (loans).

The frequency of the financial characteristics is quarterly for Bloomberg and annual for Bankscope data. In Table 5, we present the ranking of banks according to the ten

\footnotetext{
${ }^{13}$ Of course, this measure is only meaningful when there are no bank runs. Since bank runs will affect not only the deposits, but also the general funding availability, the information content of this liquidity measure is reduced during such periods.
} 
factors.

\subsection{Empirical Strategy}

We choose a particular sovereign, Spain, to be the trigger of default risk in the banking system. As previously argued, due to their small relative size, it is safe to assume that Greece, Ireland and Portugal could be bailed out if needed and hence the resulting default risk within the EU banking system could be relatively easily defused. That leaves Spain and Italy as the main concern among the GIIPS (Greece, Ireland, Italy, Portugal and Spain). The debt level of these two countries might make it infeasible to prevent a default event if they meet difficulties to service their payments (e.g. due to short-term illiquidity issues). For that reason, the ECB has continuously intervened on the debt market once Spain and Italy announced that they would issue new debt to cover their short-term funding needs.

Our set of banks is sorted by the time average of each of the financial characteristics in the previous section. We then divide the 36 banks in 9 subsets, resulting in four banks per portfolio. To each bank portfolio, we add Spain as a trigger for default risk considerations. Thus, we reduce the joint density modeling to a 5-dimensional problem. For each portfolio within each characteristic, we consider the $\triangle C O J P o D$ in case of Spain's default, resulting in 90 time series for further analysis. For the ease of exposition, we present averages of the results for three subgroups: portfolios 1 to 3,4 to 6 and 7 to 9 .

The main hypothesis in the analysis in this section is that if some financial characteristic is important for international investors, we should notice a particular ordering of $\triangle C o J P o D$ across the portfolios. For example, if leverage is an important characteristic for international investors in forming their perceptions about banking susceptibility to sovereign default, we would expect that higher-leveraged banks react more strongly to such an event. This is, of course, by no means a ceteris paribus analysis, but nonetheless, it could provide useful policy implications and important insights for further research.

\subsection{Spillover Effects from Sovereigns to Banks}

Figure 11 depicts the $\triangle C O J P o D$ results ${ }^{14}$ given a default of Spain for 9 portfolios sorted by size. The results show a clear ordering - we notice a split of our portfolios in two groups, with the biggest banks in our sample reacting much stronger to increases in Spanish default risk. Several spikes occur throughout 2008 up to the end of the global recession in mid-2009. After relatively stable 9 months, the conditional sovereign default contribution to the fragility of the biggest banks rises again in March-April 2010, and in mid-2011 it surpasses the levels during Lehman Brothers' turmoil. The higher level

\footnotetext{
${ }^{14}$ We present and interpret the results for several financial characteristics only. The rest of the results are available upon request.
} 
after July 2011 could be attributed to increased attention of markets to the problems of Italy and Spain. Our results could be explained not only by the sizeable EA sovereign debt holdings on the balance sheets of the biggest banks, but also by the uncertainty about the economic conditions in the European Union during the sample period. The high susceptibility of big banks to sovereign default risk might be related to "too-bigto-save" (Hellwig, 1998) considerations by international investors. The recent experience with the prolonged political process of bailout-packages ratification might explain why investors could be skeptical about multilateral governments' cooperation to support these international conglomerates.

With regard to leverage, Figure 12 provides a rather mixed picture. There are significant peaks during the sample period, especially in the second half of 2011, but the most vulnerable bank groups turn out to be those with relatively modest levels of leverage. This indicates that financial gearing might not be a good indicator for the reaction of banks to sovereign debt problems. An argument why leverage can provide misleading results is the fact that during crises financial institutions tend to procyclically reduce their leverage level, sometimes at a high cost, which makes them highly vulnerable to financial markets volatility.

Interestingly enough, the sorting by the return on equity (Figure 13) reveals that the market perceptions of the default risk of the highest-performing banks tend to react more intensively to sovereign default risk. The top three portfolios appear to have four to six times higher $\triangle$ CoJPoD than the second subgroup, especially in the periods around the Bear Stearns episode, the bankruptcy of Lehman Brothers and the following global recession, as well as during the more recent events, related to the sovereign debt crisis. A possible explanation might be that in international investors' view the higher performance might signal that the banks in question are involved in too risky activities.

We now turn our attention to the sorting by asset quality, measured by the doubtful loans ratio. Figure 14 provides some evidence that international investors do take asset quality into account when assessing default risk. The middle set of portfolios is consistently above the top and bottom set, but since April 2010 the banks with the highest doubtful loans ratio gradually reduce the differential. Therefore, it could be the case that in the second half of our sample period this factor might be increasingly gaining importance for international investors.

The ordering by total deposits to total funding (Figure 15) seems to follow our expectations that banks with lower values for this indicator (hence more reliant on funding from financial markets) are more vulnerable to sovereign default risk. The "correct" ordering of the portfolios is especially evident after the outbreak of the sovereign debt crisis. 


\section{Conclusion}

We introduce a new systemic risk measure, the $\triangle C O J P o D$, which assesses the effects of interdependence within the financial system on the general default risk of the financial system. The measure is related to the CoVaR and the Shapley value and captures the relationship between overall systemic fragility and individual default risk. We apply our measure to three cases: first, we estimate individual default contributions of euro area sovereigns to the systemic default risk in the euro area. Second, we investigate cascade effects among euro area sovereigns. Last, we analyze sovereign default spillover effects to the European Union banking system.

Our analysis documents an increase in systemic risk contributions due to interdependence in the EA during the post-Lehman global recession and especially after the beginning of the EA sovereign debt crisis. We also find a considerable potential for cascade effects from small to large EA sovereigns. When we investigate the effect of sovereign default on the EU banking system, we find that bigger banks, banks with riskier activities, poor asset quality, and funding and liquidity constraints tend to be more vulnerable to sovereign default.

Our results suggest that interdependence plays a major role in investors' perceptions about systemic risk in the European financial system. We find that countries with a relatively small size, like Netherlands, might have a significant systemic risk contribution if investors perceive it to be interdependent with others in the euro area. Another important conclusion from our analysis is that investors expect that it is difficult to prevent a sovereign default from spreading, once it has been triggered. The joint default of two relatively small sovereigns, like Ireland and Portugal, increases the probability of default of Spain by up to 55 percentage points and this effect has been persistent since Lehman's collapse. Therefore, our results provide support for the determined and often costly efforts of the European regulators and policy-makers to prevent a sovereign default. With regard to the analysis of spillover effects from EA sovereigns to the EU banking system, investors seem to perceive bank size, balance sheet composition and risk, and asset quality as important systemic vulnerability indicators. Therefore, regulators should allocate more resources to supervising the operations of the largest EU banks, in order to prevent the collapse of the European banking system. Surprisingly, financial gearing seems to be less informative in that respect. This might indicate that international investors consider the European banking system to be already highly leveraged and is an interesting issue for further research.

With regard to policy decision-making, there are heated debates whether euro area sovereigns should be allowed to default. The proponents of this view claim that the economic costs of a sovereign default would be lower than the size of the bailout packages to keep the sovereign solvent. The CoJPoD could be used to estimate the market 
expectations about the size of those alternative regulatory measures. To come up with meaningful regulatory suggestions pro and con a bailout package, the CoJPoD should be coupled with an estimate of the losses to the system given the respective sovereign defaults. The resulting expected loss estimate should be used to determine the size of the considered bailout package. This expected size should be then compared to the welfare costs of alternative instruments in the regulatory toolkit. Note that even if a sovereign bailout package turns out to be optimal in order to minimize social costs, it might not be feasible even with the broadest possible international cooperation. Policy makers should then resort to their remaining tools to address the consequences of a sovereign default. In either case, we hope that CoJPoD becomes a useful ingredient in the decision-making process of regulators and policy makers. 


\section{References}

[1] Acharya, V., and T. Yorulmazer, 2007, "Too Many to Fail - An Analysis of TimeInconsistency in Bank Closure Policies," Journal of Financial Intermediation, 16 (1): $1-31$.

[2] Adrian, T., and M. Brunnermeier, 2010, "CoVaR," Staff Report No. 348, Federal Reserve Bank of New York, New York, NY.

[3] Avesani, R., A. Garcia Pascual, and J. Li, 2006, "A New Risk Indicator and Stress Testing Tool: A Multifactor Nth-to-Default CDS Basket," IMF Working Paper, No. $06 / 105$.

[4] Barth, A., and I. Schnabel, 2012, "Too Big To Fail Or To Save? - Evidence from the CDS Market," Working Paper, Johannes Gutenberg University Mainz, Germany.

[5] Botev, Z., and D. Kroese, 2011, "The Generalized Cross Entropy Method, with Applications to Probability Density Estimation," Methodology and Computing in Applied Probability, 13 (1): 1-27.

[6] Boyd, J., and M. Gertler, 1994, "The Role of Large Banks in the Recent U.S. Banking Crisis," Federal Reserve Bank of Minneapolis Quarterly Review, 18(1): 2-21.

[7] Brunnermeier, M., and L. Pedersen, 2009, "Market Liquidity and Funding Liquidity," Review of Financial Studies, 22 (6): 2201-2238.

[8] Demirgüç-Kunt, A., and H. Huizinga, 2010, "Are Banks Too Big to Fail or Too Big to Save? International Evidence from Equity Prices and CDS Spreads," Policy Research Working Paper No. 5360, World Bank.

[9] EBA, 2011, "2011 EU-Wide Stress Test Aggregate Report,” European Banking Authority, July 2011.

[10] Eurostat, 2012, "Provision of deficit and debt data for 2011 - first notification," Newsrelease 62/2012, April 2012.

[11] Giglio, S., 2011, "Credit default swap spreads and systemic financial risk," Proceedings, Federal Reserve Bank of Chicago: 104-141, May 2011.

[12] Goodhart, C., and M. Segoviano, 2009, "Banking Stability Measures," IMF Working Paper 09/4.

[13] Gorea, D., and D. Radev, 2012, "Euro Area Sovereign Debt Crisis: Can Contagion Spread from the Periphery to the Core?," Working Paper, GSEFM Frankfurt-MainzDarmstadt, July 2012. 
[14] Gramlich, D., and M. Oet, 2011, "The structural fragility of financial systems: Analysis and modeling implications for early warning systems," The Journal of Risk Finance, 12(4): 270-290.

[15] Gray, D., 2011, "Enhanced Bank Stress Testing Incorporating Sovereign Risk, Funding Cost, and Liquidity Risk Using Contingent Claims Analysis (CCA)," ESRB Advisory Technical Committee Workshop, Background Paper, August 2011.

[16] Gray, D., R. Merton, and Z. Bodie, 2007, "Contingent Claims Approach to Measuring and Managing Sovereign Credit Risk," Journal of Investment Management, 5(4): 5-28.

[17] Hellwig, M., 1998, "Too big to be rescued?," Schweizer Bank 11: 1-35.

[18] Hull, J., and A. White, 2000, "Valuing credit default swaps I: No counterparty default risk," Journal of Derivatives, 8: 29-40

[19] Hüpkes, E., 2005, “"Too Big to Save” - Towards a Functional Approach to Resolving Crises in Global Financial Institutions," in Systemic Financial Crisis: Resolving large bank insolvencies: 193-215, Douglas Evanoff and George Kaufman, eds.

[20] IMF, 2011, Global Financial Stability Report, International Monetary Fund, Washington, DC, September 2011.

[21] Kaufman, G., 2002, "Too big to fail in banking: What remains?," The Quarterly Review of Economics and Finance, 42(3): 423-436.

[22] Kullback, S., 1959, "Information Theory and Statistics," John Wiley, New York.

[23] Lehar, A, 2005, "Measuring Systemic Risk: A Risk Management Approach," Journal of Banking and Finance, 29(10): 2577-2603.

[24] Merton, R., 1974, "On the Pricing of Corporate Debt: The Risk Structure of Interest Rates," The Journal of Finance, 29: 449-470.

[25] O'Kane, D., and S. Turnbull, 2003, "Valuation of Credit Default Swaps," Lehman Brothers, Fixed Income Quantitative Credit Research.

[26] Peña, J., and M. Rodriguez-Moreno, 2010, "Systemic Risk Measures: The Simpler the Better?," Working Paper 10-31, Business Economic Series 05, Universidad Carlos III de Madrid.

[27] Radev, D., 2012, "Assessing Systemic Fragility: A Probabilistic Perspective," Working Paper, Johannes Gutenberg University Mainz.

[28] Rime, B., 2005, "Do "too big to fail" expectations boost large banks issuer ratings?," Swiss National Bank Working Paper. 
[29] Segoviano, M., 2006, "Consistent Information Multivariate Density Optimizing Methodology," FMG Discussion Papers dp557, Financial Markets Group.

[30] Sturzenegger, F., and J. Zettelmeyer, 2005, "Haircuts: Estimating Investor Losses in Sovereign Debt Restructurings, 1998-2005 ," IMF Working Paper, WP/05/137.

[31] Tarashev, N, C. Borio, and K. Tsatsaronis, 2010, "The systemic importance of financial institutions," BIS Working Papers, 308.

[32] Völz, M., and M. Wedow, 2009, "Market discipline and too-big-to-fail in the CDS market: Does banks' size reduce market discipline? Does banks' size distort market prices? Evidence for too-big-to-fail in the CDS market," Journal of Empirical Finance, 18: 195-210.

[33] Zhang, X., B. Schwaab, and A. Lucas, 2012, "Conditional probabilities and contagion measures for Euro Area sovereign default risk," Working Paper, VU University Amsterdam, January 12, 2012.

[34] Zhou, C., 2010, "Are Banks Too Big to Fail? Measuring Systemic Importance of Financial Institutions," International Journal of Central Banking, 6(4): 205-250. 


\section{A Solutions and Proofs}

\section{A.1 CDS Bootstrapping Procedure}

If $\tau$ is the time to default, one can express the probability of default at market date $t$, $\operatorname{PoD}(\mathrm{t})$ as

$$
P o D(t)=P[\tau \leq t]=1-P[\tau \geq t]=1-Q(t)
$$

where $[\tau \leq t]$ and $P[\tau \geq t]=Q(t)$ are the probability of the time to default to be less than $t$ and the survival probability, respectively.

We apply a standard survival probability model by expressing $Q(t)$ via a piecewise constant hazard rate $h(t)$. For instance, given that

$$
h(t)= \begin{cases}\gamma_{1} & \text { for } 0 \leq t \leq t_{1} \\ \gamma_{2} & \text { for } t_{1}<t \leq t_{2} \\ \gamma_{3} & \text { for } t_{2}<t\end{cases}
$$

the survival function is

$$
Q(t)= \begin{cases}e^{\gamma_{1} \cdot t} & \text { for } 0 \leq t \leq t_{1}, \\ e^{\gamma_{1} \cdot t-\gamma_{2} \cdot\left(t-t_{1}\right)} & \text { for } t_{1}<t \leq t_{2}, \\ e^{\gamma_{1} \cdot t_{1}-\gamma_{2} \cdot\left(t_{2} 2-t_{1}\right)-\gamma_{3} \cdot\left(t-t_{2}\right)} & \text { for } t_{2}<t\end{cases}
$$

The CDS bootstrapping procedure then calibrates $\gamma_{1}, \gamma_{2}$ and $\gamma_{3}$ to the market CDS premia data $S_{1}, S_{2}$ and $S_{3}$, such that the present value of the payment in case of default (100\% - recovery rate), called also the "protection leg", equals the discounted premia flows in the CDS contract, or the "premium leg" at the given market dates $t_{1}, t_{3}$ and $t_{3}$. This equality relies on the no-arbitrage condition on financial markets. In practice this is an iterative procedure that starts with the shortest maturity contract to calculate the first hazard rate, $\gamma_{1}$, and works its way through to the longest maturity, making sure that the no-arbitrage condition holds at each step. In our calculation, we also account for the quarterly structure of the CDS contract and the accrued premium that should be paid, given the default is anywhere in between any two market dates. We then use Equation survpod to calculate our cumulative $\operatorname{Po} D(t)$, with $t=1, \ldots, T$ denoting the default horizon $\left(\mathrm{T}=5\right.$ years in our case). Effectively, we use $\operatorname{PoD}(T)$ and annualize it using Formula $8{ }^{15}$

\footnotetext{
${ }^{15}$ Note the innocuous abuse of notation: in the text we use index $t$ to denote each date in our sample, while here, we use it to denote a particular time horizon.
} 


\section{A.2 Consistent Information Multivariate Density Optimizing Approach}

We proceed by defining the financial system as a portfolio of debt issuers. ${ }^{16}$ We observe $n$ issuers, namely the $X_{1}, X_{2}$ to $X_{n}$ entities defined in Section 2.1, with corresponding assets $x_{1}, x_{2}$, to $x_{n}$. We define our objective function as:

$$
\chi(p, q)=\int_{-\infty}^{+\infty} \int_{-\infty}^{+\infty} \cdots \int_{-\infty}^{+\infty} p\left(x_{1}, x_{2}, \ldots, x_{n}\right) \ln \left[\frac{p\left(x_{1}, x_{2}, \ldots, x_{n}\right)}{q\left(x_{1}, x_{2}, \ldots, x_{n}\right)}\right] d x_{1} \cdots d x_{n-1} d x_{n}
$$

The function $q\left(x_{1}, x_{2}, \ldots, x_{n}\right) \in \mathbb{R}^{n}$ stands for the multivariate prior density function, ${ }^{17}$ while $p\left(x_{1}, x_{2}, \ldots, x_{n}\right) \in \mathbb{R}^{n}$ is the corresponding posterior density. The primary objective of the minimum cross-entropy approach is to minimize the difference $\chi(p, q)$ between the ex ante joint distribution $q(\cdot)$ and the ex post joint distribution $p(\cdot)$, given that the latter fulfills a set of constraints on the tail mass of the underlying marginal distributions. This set of constraints should relate the posterior distribution to empirical data:

$$
\begin{aligned}
& \int_{-\infty}^{+\infty} \int_{-\infty}^{+\infty} \cdots \int_{-\infty}^{+\infty} p\left(x_{1}, x_{2}, \ldots, x_{n}\right) \mathbf{I}_{\left.\overline{\mathbf{x}}_{1}, \infty\right)} d x_{1} \cdots d x_{n-1} d x_{n}=P_{O} D_{t}^{1} \\
& \int_{-\infty}^{+\infty} \int_{-\infty}^{+\infty} \cdots \int_{-\infty}^{+\infty} p\left(x_{1}, x_{2}, \ldots, x_{n}\right) \mathbf{I}_{\left.\overline{\mathbf{x}}_{x_{2}}, \infty\right)} d x_{1} \cdots d x_{n-1} d x_{n}=P_{O} D_{t}^{2} \\
& \int_{-\infty}^{+\infty} \int_{-\infty}^{+\infty} \cdots \int_{-\infty}^{+\infty} p\left(x_{1}, x_{2}, \ldots, x_{n}\right) \mathbf{I}_{\left[\overline{\mathbf{x}}_{x_{n}}, \infty\right)} d x_{1} \cdots d x_{n-1} d x_{n}=P_{O} D_{t}^{n},
\end{aligned}
$$

where $P o D_{t}^{1}, P_{o} D_{t}^{2}$ to $P o D_{t}^{n}$ stand for the CDS-derived expected probabilities of default of $X_{1}, X_{2}, \ldots, X_{n}$. The indicator functions $\mathbf{I}_{\left[\overline{\mathbf{x}}_{1}, \infty\right)}, \mathbf{I}_{\left.\overline{\mathbf{x}}_{2}, \infty\right)}$ to $\mathbf{I}_{\left.\overline{\mathbf{x}}_{n}, \infty\right)}$ incorporate the default thresholds $\overline{\mathbf{x}}_{1}, \overline{\mathbf{x}}_{2}$ to $\overline{\mathbf{x}}_{n}{ }^{18}$ of the respective institutions. The functions take the value of unity if the assets of the respective entities exceed their individual thresholds and zero when they are below it. As explained above, the moment consistency

\footnotetext{
${ }^{16}$ In this section, we present the multivariate version of the CIMDO approach. For the bivariate and trivariate models, please refer to Gorea and Radev (2012) and Segoviano (2006).

${ }^{17} \mathrm{As}$ in Segoviano and Goodhart (2009), we assume a standard multivariate normal distribution for our prior. The prior density $q$ is then $\frac{1}{(2 \pi)^{\frac{n}{2}}|\Sigma|^{\frac{1}{2}}} e^{\left(\frac{1}{2} \mathbf{x}^{\prime} \Sigma^{-1} \mathbf{x}\right)}$, where $\mathbf{x}$ is an $n$-dimensional random vector, while $\Sigma$ is an $n \times n$ variance-covariance matrix of standard-normally-distributed variables (mean zero and standard deviation equal to one). In contrast to Segoviano and Goodhart (2009), we assume an arbitrary correlation structure, instead of the identity matrix.

${ }^{18}$ Each default threshold is derived by inverting a univariate standard normal cumulative distribution function at the sample average value of the individual entity's probabilities of default.
} 
constraints should ensure that the region of default of the "posterior" distribution is consistent with the market consensus default expectations for each sovereign or bank. In addition, in order to qualify as a density, $p(\cdot)$ should conform to the additivity constraint $\int_{-\infty}^{+\infty} \int_{-\infty}^{+\infty} \cdots \int_{-\infty}^{+\infty} p\left(x_{1}, x_{2}, \ldots, x_{n}\right) d x_{1} \cdots d x_{n-1} d x_{n}=1$

We then minimize the Lagrangian function:

$$
\begin{aligned}
\mathcal{L}(p, q) & =\int_{-\infty}^{+\infty} \int_{-\infty}^{+\infty} \ldots \int_{-\infty}^{+\infty} p\left(x_{1}, x_{2}, \ldots, x_{n}\right) \ln \left[\frac{p\left(x_{1}, x_{2}, \ldots, x_{n}\right)}{q\left(x_{1}, x_{2}, \ldots, x_{n}\right)}\right] d x_{1} \cdots d x_{n-1} d x_{n} \\
& +\lambda_{1}\left[\int_{-\infty}^{+\infty} \int_{-\infty}^{+\infty} \ldots \int_{-\infty}^{+\infty} p\left(x_{1}, x_{2}, \ldots, x_{n}\right) \mathbf{I}_{\left.\overline{\mathbf{x}}_{1}, \infty\right)} d x_{1} \cdots d x_{n-1} d x_{n}-P_{o} D_{t}^{1}\right] \\
& +\lambda_{2}\left[\int_{-\infty}^{+\infty} \int_{-\infty}^{+\infty} \ldots \int_{-\infty}^{+\infty} p\left(x_{1}, x_{2}, \ldots, x_{n}\right) \mathbf{I}_{\left.\overline{\mathbf{x}}_{2}, \infty\right)} d x_{1} \cdots d x_{n-1} d x_{n}-P_{o} D_{t}^{2}\right] \\
& +\cdots\left[\int_{n}\left[\int_{-\infty}^{+\infty} \ldots \int_{-\infty}^{+\infty} p\left(x_{1}, x_{2}, \ldots, x_{n}\right) \mathbf{I}_{\left[\overline{\mathbf{x}}_{n}, \infty\right)} d x_{1} \cdots d x_{n-1} d x_{n}-P_{o} D_{t}^{n}\right]\right. \\
& \left.+\lambda_{-\infty}^{+\infty} \int_{-\infty}^{+\infty} \ldots \int_{-\infty}^{+\infty} p\left(x_{1}, x_{2}, \ldots, x_{n}\right) d x_{1} \cdots d x_{n-1} d x_{n}-1\right]
\end{aligned}
$$

with $\mu, \lambda_{1}, \lambda_{2}$ to $\lambda_{n}$ being the Lagrange multipliers of the corresponding constraints. The optimal ex post distribution reads: ${ }^{19}$

$$
p^{*}\left(x_{1}, x_{2}, \ldots, x_{n}\right)=q\left(x_{1}, x_{2}, \ldots, x_{n}\right) \exp \left\{-\left[1+\mu+\sum_{i=1}^{n} \lambda_{i} \mathbf{I}_{\left[\overline{\mathbf{x}}_{i}, \infty\right)}\right]\right\} .
$$

The posterior distribution has two important properties: first, regardless of the prior assumption, the ex post distribution allows for fat tails and second, due to the dynamic updating through the individual empirical information, the posterior joint distribution is time-varying by construction.

\footnotetext{
${ }^{19}$ Appendix A.3 contains a detailed solution of the minimum cross-entropy optimization problem in a CIMDO context.
} 


\section{A.3 Solution of Minimum Cross Entropy}

The minimum cross entropy procedure can be viewed as a part of an iterative algorithm to approximate a target probability density $f$, using empirical data describing its underlying unknown process. ${ }^{20}$ In this procedure, an a-priori (or prior) density $q$ is updated to a posterior density $p$, given the following Cross Entropy Postulate:

1. Conditional on a prior density $q$ of a set $\mathfrak{X} \subset \Re^{d}$,

2. we minimize the Csiszár Cross Entropy measure ${ }^{21}$

$$
\mathcal{D}(p \rightarrow q)=\int_{\mathfrak{X}} q(\mathbf{x}) \cdot \psi\left(\frac{p(\mathbf{x})}{q(\mathbf{x})}\right) d \mathbf{x}
$$

with respect to $p(\mathbf{x})$, where $\mathbf{x}$ is a column vector and $\mathbf{x} \in \Re^{d}$,

3. given the moment constraints

$$
\mathbb{E}_{p} K_{i}(\mathbf{X})=\int_{\mathfrak{X}} p(\mathbf{x}) \cdot K_{i}(\mathbf{x}) d \mathbf{x}=\hat{\kappa}_{i}, i=0, \ldots, n,
$$

where $\left\{K_{i}(\mathbf{x})\right\}_{i=1}^{n}$ is a set of suitably chosen functions and $\hat{\kappa}_{i}$ is empirical information describing the behaviour of the system, $\mathbb{E}_{f} K_{i}(\mathbf{X})$.

The Minimum Cross Entropy Problem is then defined as

$$
\min _{p} \mathcal{D}(p \rightarrow q)
$$

subject to the constraints

$$
\int_{\mathfrak{X}} p(\mathbf{x}) \cdot K_{i}(\mathbf{x}) d \mathbf{x}=\hat{\kappa}_{i}, i=0, \ldots, n
$$

and

$$
\int p(\mathbf{x}) d \mathbf{x}=1
$$

The corresponding Lagrangian is then

\footnotetext{
${ }^{20}$ For further details on the cross-entropy method and its generalizations, please consult with e. g. Botev and Kroese (2011).

${ }^{21}$ The Csiszár Cross Entropy measure is a measure of directed divergence between probability densities (Botev and Kroese, 2011).
} 


$$
\begin{aligned}
\mathcal{L}\left(p ; \boldsymbol{\lambda}, \lambda_{0}\right) & = \\
& =\int q(\mathbf{x}) \cdot \psi\left(\frac{p(\mathbf{x})}{q(\mathbf{x})}\right) d \mathbf{x}+\lambda_{0}\left(1-\int p(\mathbf{x}) d \mathbf{x}\right)+\sum_{i=1}^{n} \lambda_{i}\left(\hat{\kappa}_{i}-\int p(\mathbf{x}) \cdot K_{i}(\mathbf{x}) d \mathbf{x}\right) \\
& =\sum_{i=0}^{n} \lambda_{i} \cdot \hat{\kappa}_{i}+\int\left(q(\mathbf{x}) \cdot \psi\left(\frac{p(\mathbf{x})}{q(\mathbf{x})}\right)+p(\mathbf{x}) \cdot \sum_{i=0}^{n} \lambda_{i} \cdot K_{i}(\mathbf{x})\right) d \mathbf{x},
\end{aligned}
$$

where $\boldsymbol{\lambda}=\left[\lambda_{1}, \lambda_{2}, \ldots, \lambda_{n}\right]^{T}, \hat{\kappa}_{0}=1$, and $K_{0}(\cdot)=1$.

Let us assume that $\left\{K_{i}(\mathbf{x})\right\}_{i=0}^{n}=\left\{I_{i}(\mathbf{x})\right\}_{i=0}^{n}$, where $I_{i}, i=1,2, \ldots, n$ are binary functions taking values of unity when the respective $x_{i}$ satisfies some condition, and zero otherwise, and $I_{0}=1$. The first order condition with respect to $p(\mathbf{x})$ is then

$$
\frac{\partial\left(q(\mathbf{x}) \cdot \psi\left(\frac{p(\mathbf{x})}{q(\mathbf{x})}\right)+p(\mathbf{x}) \cdot \sum_{i=0}^{n} \lambda_{i} \cdot \mathbf{I}_{i}\right)}{\partial p(\mathbf{x})} \stackrel{!}{=} 0 .
$$

The latter can be further simplified as follows:

$$
\begin{gathered}
q(\mathbf{x}) \cdot(q(\mathbf{x}))^{-1} \cdot \psi^{\prime}\left(\frac{p(\mathbf{x})}{q(\mathbf{x})}\right)+\sum_{i=0}^{n} \lambda_{i} \cdot \mathbf{I}_{i}=0 \\
\psi^{\prime}\left(\frac{p(\mathbf{x})}{q(\mathbf{x})}\right)=-\sum_{i=0}^{n} \lambda_{i} \cdot \mathbf{I}_{i} .
\end{gathered}
$$

Assume $\psi(\mathbf{x})=\mathbf{x} \cdot \ln (\mathbf{x})$, which is referred to in the literature as the Kullback-Leibler distance $^{22}$. The Csiszár Cross Entropy measure can then me transformed as

$$
\begin{aligned}
\int q(\mathbf{x}) \cdot \psi\left(\frac{p(\mathbf{x})}{q(\mathbf{x})}\right) & =\int q(\mathbf{x}) \cdot \frac{p(\mathbf{x})}{q(\mathbf{x})} \cdot \ln \left(\frac{p(\mathbf{x})}{q(\mathbf{x})}\right) \\
& =\int p(\mathbf{x}) \cdot \ln \left(\frac{p(\mathbf{x})}{q(\mathbf{x})}\right),
\end{aligned}
$$

while our $\psi^{\prime}\left(\frac{p(\mathbf{x})}{q(\mathbf{x})}\right)$ takes the form

$$
\begin{aligned}
\psi^{\prime}\left(\frac{p(\mathbf{x})}{q(\mathbf{x})}\right) & =\left(\frac{p(\mathbf{x})}{q(\mathbf{x})} \cdot \ln \left(\frac{p(\mathbf{x})}{q(\mathbf{x})}\right)\right)^{\prime} \\
& =\ln \left(\frac{p(\mathbf{x})}{q(\mathbf{x})}\right)+\frac{p(\mathbf{x})}{q(\mathbf{x})} \cdot\left(\frac{p(\mathbf{x})}{q(\mathbf{x})}\right)^{-1} \\
& =\ln \left(\frac{p(\mathbf{x})}{q(\mathbf{x})}\right)+1 .
\end{aligned}
$$

\footnotetext{
${ }^{22}$ The Kullback-Leibler distance is a usual assumption that allows us to avoid setting additional constraints to secure the non-negativity of $p(\mathbf{x})$.
} 
Substituting in our first order condition Equation (29) and simplifying further yields

$$
\begin{aligned}
& \ln \left(\frac{p(\mathbf{x})}{q(\mathbf{x})}\right)+1=-\sum_{i=0}^{n} \lambda_{i} \cdot \mathbf{I}_{i} \\
& \ln \left(\frac{p(\mathbf{x})}{q(\mathbf{x})}\right)=-1-\sum_{i=0}^{n} \lambda_{i} \cdot \mathbf{I}_{i} .
\end{aligned}
$$

The solution to the Minimum Cross Entropy problem is then

$$
p(\mathbf{x})=q(\mathbf{x}) \cdot \exp \left\{-\left[1+\sum_{i=0}^{n} \lambda_{i} \mathbf{I}_{i}\right]\right\} .
$$

Changing the notation of the Lagrange multiplier of the additivity constraint to $\mu$, we arrive at

$$
p(\mathbf{x})=q(\mathbf{x}) \cdot \exp \left\{-\left[1+\mu+\sum_{i=1}^{n} \lambda_{i} \mathbf{I}_{i}\right]\right\},
$$

which is the general form of the solution to the CIMDO minimization problem. 


\section{A.4 Proof of Independence within the Default Region of the CIMDO Distribution}

To prove independence, we want to show that using standard normal distribution as a prior, the following holds for the posterior CIMDO distribution and its marginals:

$$
\begin{aligned}
P\left(x_{1}>\overline{\mathbf{x}}_{1}, x_{2}>\overline{\mathbf{x}}_{2}, \ldots, x_{n}>\overline{\mathbf{x}}_{n}\right) & =P\left(x_{1}>\overline{\mathbf{x}}_{1}\right) \cdot P\left(x_{2}>\overline{\mathbf{x}}_{2}\right) \cdots P\left(x_{n}>\overline{\mathbf{x}}_{n}\right) \\
& =\prod_{i=1}^{n} P\left(x_{i}>\overline{\mathbf{x}}_{i}\right),
\end{aligned}
$$

where $P\left(x_{1}>\overline{\mathbf{x}}_{1}\right), P\left(x_{2}>\overline{\mathbf{x}}_{2}\right), \ldots, P\left(x_{n}>\overline{\mathbf{x}}_{n}\right)$ and $P\left(x_{1}>\overline{\mathbf{x}}_{1}, x_{2}>\overline{\mathbf{x}}_{2}, \ldots, x_{n}>\overline{\mathbf{x}}_{n}\right)$ are the cumulative marginal and joint CIMDO probabilities.

\section{Proof:}

We present a direct proof of the statement above. We start by expressing $P\left(x_{n}>\overline{\mathbf{x}}_{n}\right)$, $P\left(x_{1}>\overline{\mathbf{x}}_{1}, x_{2}>\overline{\mathbf{x}}_{2}, \ldots, x_{n-1}>\overline{\mathbf{x}}_{n-1}\right)$ and $P\left(x_{1}>\overline{\mathbf{x}}_{1}, x_{2}>\overline{\mathbf{x}}_{2}, \ldots, x_{n}>\overline{\mathbf{x}}_{n}\right)$ in terms of the prior (multivariate standard normal) distribution and the thresholds $\overline{\mathbf{x}}_{1}, \overline{\mathbf{x}}_{2}$ to $\overline{\mathbf{x}}_{n}$ :

$$
\begin{aligned}
& P\left(x_{n}>\overline{\mathbf{x}}_{n}\right)=P_{O} D^{n} \\
& =\int_{-\infty}^{+\infty} \int_{-\infty}^{+\infty} \cdots \int_{-\infty}^{+\infty} p\left(x_{1}, x_{2}, \ldots, x_{n}\right) \mathbf{I}_{\left[\overline{\mathbf{x}}_{n}, \infty\right)} d x_{1} \cdots d x_{n-1} d x_{n} \\
& =\int_{\overline{\mathbf{x}}_{n}}^{+\infty} \int_{-\infty}^{+\infty} \cdots \int_{-\infty}^{+\infty}(2 \pi)^{\frac{n}{2}} e^{\left(-\frac{\sum_{i=1}^{n} x_{i}^{2}}{2}\right)} e^{\left(-\left(1+\mu+\sum_{i=1}^{n-1} \lambda_{i} \mathbf{I}_{\left.\overline{\mathbf{x}}_{i}, \infty\right)}+\lambda_{n}\right)\right)} d x_{1} \cdots d x_{n-1} d x_{n}, \\
& P\left(x_{1}>\overline{\mathbf{x}}_{1}, x_{2}>\overline{\mathbf{x}}_{2}, \ldots, x_{n-1}>\overline{\mathbf{x}}_{n-1}\right)= \\
& =\int_{-\infty}^{+\infty} \int_{-\infty}^{+\infty} \cdots \int_{-\infty}^{+\infty} p\left(x_{1}, x_{2}, \ldots, x_{n}\right) \mathbf{I}_{\left[\overline{\mathbf{x}}_{1}, \infty\right)} \cdot \mathbf{I}_{\left[\overline{\mathbf{x}}_{2}, \infty\right)} \cdots \mathbf{I}_{\left.\overline{\mathbf{x}}_{n-1}, \infty\right)} d x_{1} \cdots d x_{n-1} d x_{n} \\
& =\int_{-\infty}^{+\infty} \int_{\overline{\mathbf{x}}_{n-1}}^{+\infty} \cdots \int_{\overline{\mathbf{x}}_{1}}^{+\infty}(2 \pi)^{\frac{n}{2}} e^{\left(-\frac{\sum_{i=1}^{n} x_{i}^{2}}{2}\right)} e^{\left(-\left(1+\mu+\sum_{i=1}^{n-1} \lambda_{i}+\lambda_{n} \mathbf{I}_{\left[\overline{\mathbf{x}}_{n}, \infty\right)}\right)\right)} d x_{1} \cdots d x_{n-1} d x_{n}
\end{aligned}
$$

where $\mathbf{I}_{\left[\overline{\mathbf{x}}_{1}, \infty\right)}, \mathbf{I}_{\left[\overline{\mathbf{x}}_{2}, \infty\right)}$ to $\mathbf{I}_{\left[\overline{\mathbf{x}}_{n}, \infty\right)}$ are indicator functions that take the value of one in the cases where the assets of $X_{1}, X_{2}$ to $X_{n}$ are beyond their individual thresholds, respectively. Then, the joint probability of distress is as follows: 


$$
\begin{aligned}
& P\left(x_{1}>\overline{\mathbf{x}}_{1}, x_{2}>\overline{\mathbf{x}}_{2}, \ldots, x_{n}>\overline{\mathbf{x}}_{n}\right)= \\
& =\int_{-\infty}^{+\infty} \int_{-\infty}^{+\infty} \cdots \int_{-\infty}^{+\infty} p\left(x_{1}, x_{2}, \ldots, x_{n}\right) \mathbf{I}_{\left[\overline{\mathbf{x}}_{1}, \infty\right)} \cdot \mathbf{I}_{\left[\overline{\mathbf{x}}_{2}, \infty\right)} \cdots \mathbf{I}_{\left[\overline{\mathbf{x}}_{n}, \infty\right)} d x_{1} \cdots d x_{n-1} d x_{n} \\
& =\int_{\overline{\mathbf{x}}_{n}}^{+\infty} \int_{\overline{\mathbf{x}}_{n-1}}^{+\infty} \cdots \int_{\overline{\mathbf{x}}_{1}}^{+\infty}(2 \pi)^{\frac{n}{2}} e^{\left(-\frac{\sum_{i=1}^{n} x_{i}^{2}}{2}\right)} e^{\left(-\left(1+\mu+\sum_{i=1}^{n} \lambda_{i}\right)\right)} d x_{1} \cdots d x_{n-1} d x_{n} .
\end{aligned}
$$

Rearranging $P\left(x_{n}>\overline{\mathbf{x}}_{n}\right)$, we get

$$
\begin{aligned}
& P\left(x_{n}>\overline{\mathbf{x}}_{n}\right)= \\
& =\int_{\overline{\mathbf{x}}_{n}}^{+\infty}(2 \pi)^{-\frac{1}{2}} e^{-\frac{x_{n}^{2}}{2}} e^{-\lambda_{n}} d x_{n} \int_{-\infty}^{+\infty} \cdots \int_{-\infty}^{+\infty}(2 \pi)^{\frac{n-1}{2}} e^{\left(\begin{array}{c}
\sum^{n-1} x_{i}^{2} \\
-\frac{i=1}{2}
\end{array}\right)} e^{\left(-\left(1+\mu+\sum_{i=1}^{n-1} \lambda_{i} \mathbf{I}_{\left.\mathbf{x}_{i}, \infty\right)}\right)\right)} d x_{1} \cdots d x_{n-1} .
\end{aligned}
$$

Analogously, for $P\left(x_{1}>\overline{\mathbf{x}}_{1}, x_{2}>\overline{\mathbf{x}}_{2}, \ldots, x_{n-1}>\overline{\mathbf{x}}_{n-1}\right)$, we come at:

$$
\begin{aligned}
& P\left(x_{1}>\overline{\mathbf{x}}_{1}, x_{2}>\overline{\mathbf{x}}_{2}, \ldots, x_{n-1}>\overline{\mathbf{x}}_{n-1}\right)= \\
& =\int_{\overline{\mathbf{x}}_{n-1}}^{+\infty} \cdots \int_{\overline{\mathbf{x}}_{1}}^{+\infty}(2 \pi)^{\frac{n-1}{2}} e^{\left(-\frac{\sum_{i=1}^{n-1} x_{i}^{2}}{2}\right)} e^{\left(-\sum_{i=1}^{n-1} \lambda_{i}\right)} d x_{1} \cdots d x_{n-1} \int_{-\infty}^{+\infty}(2 \pi)^{-\frac{1}{2}} e^{-\frac{x_{n}^{2}}{2}} e^{\left(-\left(1+\mu+\lambda_{n} \mathbf{I}_{\left.\left.\overline{\mathbf{x}}_{n}, \infty\right)\right)}\right.\right.} d x_{n},
\end{aligned}
$$

Hence, for the product of the latter probabilities, we have:

$$
\begin{aligned}
& P\left(x_{1}>\overline{\mathbf{x}}_{1}, x_{2}>\overline{\mathbf{x}}_{2}, \ldots, x_{n-1}>\overline{\mathbf{x}}_{n-1}\right) \cdot P\left(x_{n}>\overline{\mathbf{x}}_{n}\right)= \\
& =\left[\int_{\overline{\mathbf{x}}_{n-1}}^{+\infty} \cdots \int_{\overline{\mathbf{x}}_{1}}^{+\infty}(2 \pi)^{\frac{n-1}{2}} e^{\left(\begin{array}{c}
n-1 \\
-\frac{\sum_{i=1}^{2}}{2}
\end{array}\right)} e^{\left(-\sum_{i=1}^{n-1} \lambda_{i}\right)} d x_{1} \cdots d x_{n-1} \int_{-\infty}^{+\infty}(2 \pi)^{-\frac{1}{2}} e^{-\frac{x_{n}^{2}}{2}} e^{\left(-\left(1+\mu+\lambda_{n} \mathbf{I}_{\left.\left.\left[\overline{\mathbf{x}}_{n}, \infty\right)\right)\right)}\right.\right.} d x_{n}\right] \\
& {\left[\int_{\overline{\mathbf{x}}_{n}}^{+\infty}(2 \pi)^{-\frac{1}{2}} e^{-\frac{x_{n}^{2}}{2}} e^{-\lambda_{n}} d x_{n} \int_{-\infty}^{+\infty} \cdots \int_{-\infty}^{+\infty}(2 \pi)^{\frac{n-1}{2}} e^{\left(\begin{array}{c}
n-1 \\
-\frac{\sum_{i=1}^{2} x_{i}^{2}}{2}
\end{array}\right)} e^{\left(-\left(1+\mu+\sum_{i=1}^{n-1} \lambda_{i} \mathbf{I}_{\left.\left.\left.\mathbf{[} \bar{x}_{i}, \infty\right)\right)\right)}\right.\right.} d x_{1} \cdots d x_{n-1}\right]} \\
& =\left[\int_{\overline{\mathbf{x}}_{n}}^{+\infty} \int_{\overline{\mathbf{x}}_{n-1}}^{+\infty} \cdots \int_{\overline{\mathbf{x}}_{1}}^{+\infty}(2 \pi)^{\frac{n}{2}} e^{\left(-\frac{\sum_{i=1}^{n} x_{i}^{2}}{2}\right)} e^{\left(-\left(1+\mu+\sum_{i=1}^{n} \lambda_{i}\right)\right)} d x_{1} \cdots d x_{n-1} d x_{n}\right] \\
& {\left[\int_{-\infty}^{+\infty} \int_{-\infty}^{+\infty} \cdots \int_{-\infty}^{+\infty}(2 \pi)^{\frac{n}{2}} e^{\left(-\frac{\sum_{i=1}^{n} x_{i}^{2}}{2}\right)} e^{\left(-\left(1+\mu+\sum_{i=1}^{n} \lambda_{i} \mathbf{I}_{\left[\bar{x}_{i}, \infty\right)}\right)\right)} d x_{1} \cdots d x_{n-1} d x_{n}\right]}
\end{aligned}
$$


As the integral in the last square brackets is in fact the additivity constraint in our optimization problem, it equals 1 by definition. The remaining term equals our definition for the joint probability $P\left(x_{1}>\overline{\mathbf{x}}_{1}, x_{2}>\overline{\mathbf{x}}_{2}, \ldots, x_{n}>\overline{\mathbf{x}}_{n}\right)$. If we repeat the procedure iteratively for the joint distributions $P\left(x_{1}>\overline{\mathbf{x}}_{1}, x_{2}>\overline{\mathbf{x}}_{2}, \ldots, x_{i}>\overline{\mathbf{x}}_{i}\right)$, for $i=n-1, \ldots, 2$, we arrive at the following decomposition:

$$
\begin{aligned}
P\left(x_{1}>\overline{\mathbf{x}}_{1}, x_{2}>\overline{\mathbf{x}}_{2}, \ldots, x_{n}>\overline{\mathbf{x}}_{n}\right) & =P\left(x_{1}>\overline{\mathbf{x}}_{1}\right) \cdot P\left(x_{2}>\overline{\mathbf{x}}_{2}\right) \cdots P\left(x_{n}>\overline{\mathbf{x}}_{n}\right) \\
& =\prod_{i=1}^{n} P\left(x_{i}>\overline{\mathbf{x}}_{i}\right) .
\end{aligned}
$$

Hence, the product of the marginal probabilities of distress $P\left(x_{1}>\overline{\mathbf{x}}_{1}\right), P\left(x_{2}>\overline{\mathbf{x}}_{2}\right), \ldots$, and $P\left(x_{n}>\overline{\mathbf{x}}_{n}\right)$ equals the joint probability of distress, meaning that within the joint distress region, the entities $X_{1}, X_{2}$ and $X_{n}$ are independent. 


\section{B Figures}

Figure 1: 5-year annualized CDS-implied probabilities of default of Greece, using the simple formula 7 (GR(simple)) and the bootstrapping procedure (GR). The 5-year annualized CDS-implied bootstrapped probabilities of default are derived from the respective cumulative ones using formula 8. Euro-denominated CDS spreads are used. Period: 01.01.2008 - 31.12.2011. Source: own calculations.

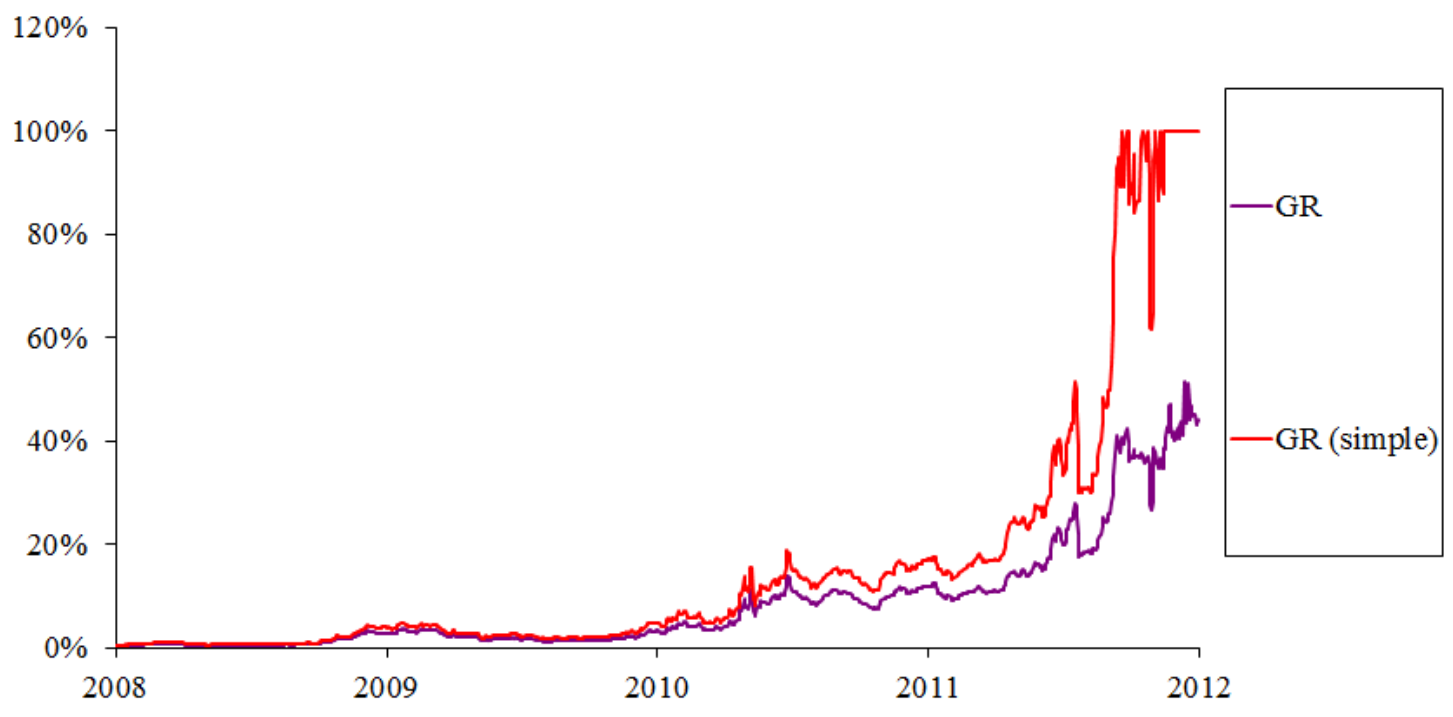




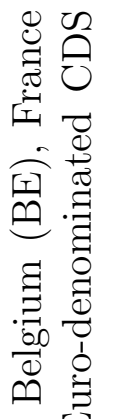

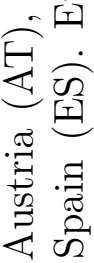

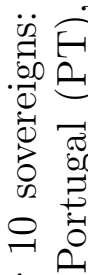

훙.

壱

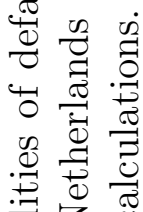

要画

a

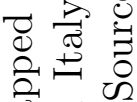

氙的.

용

믈 곡

品

定

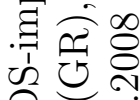

Oิ

\&

둥

言琶象

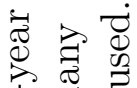

เo

त

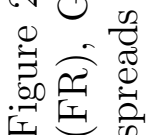

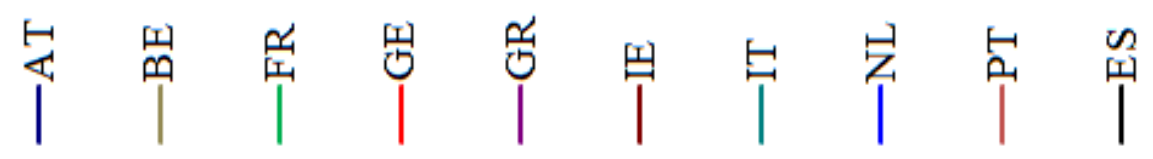
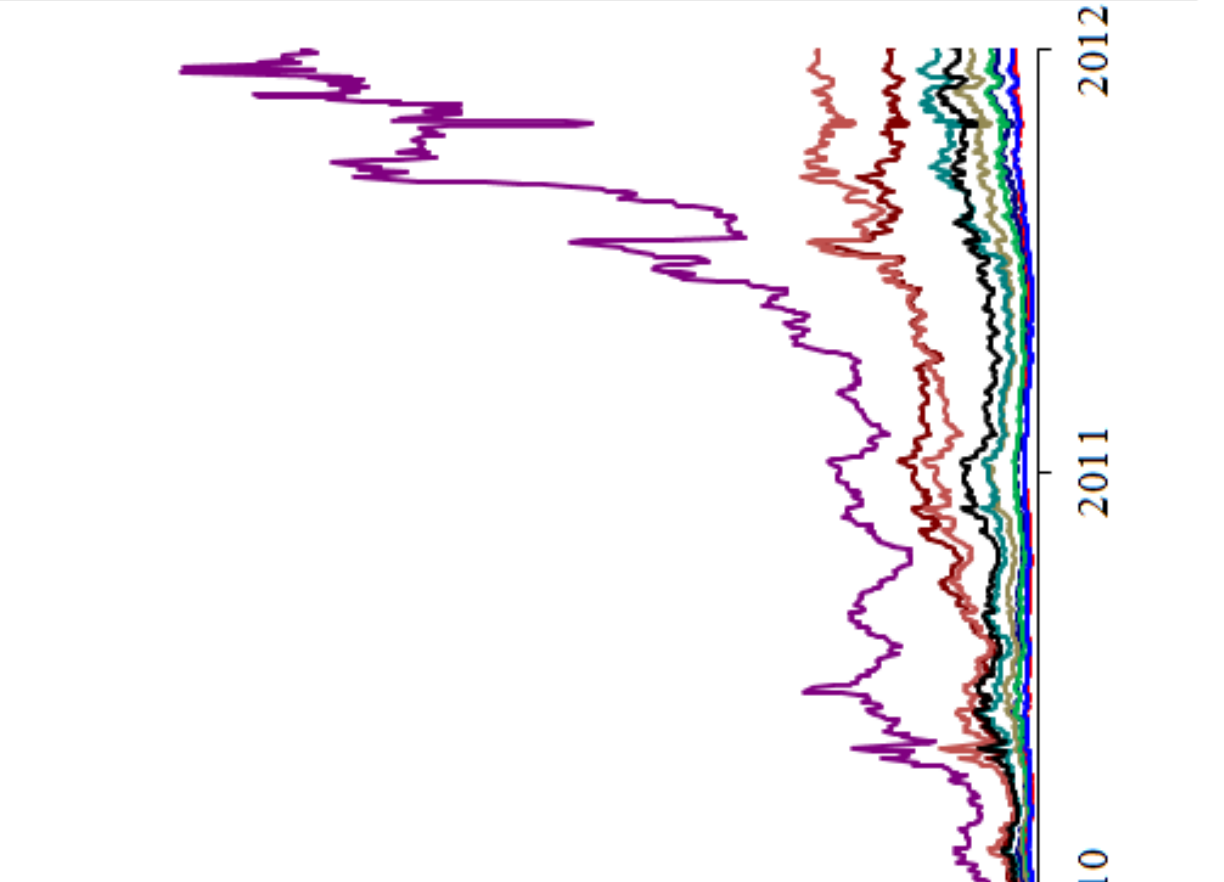

웅

- 
पै

范

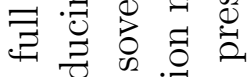

\&

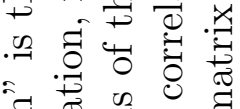

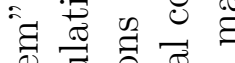

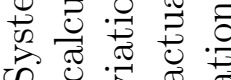

S

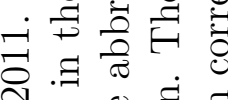

궈요 छ

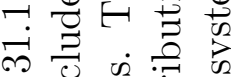

1.

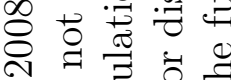

ำ

की

○.0

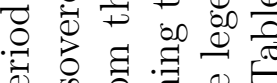

क व

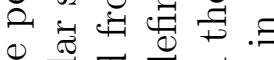

过

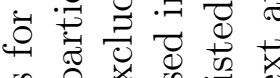

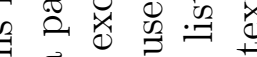

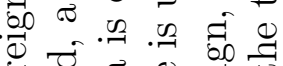

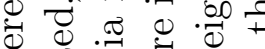

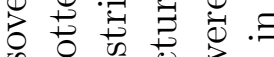

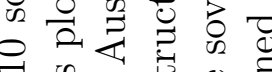

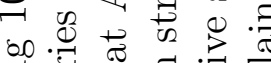

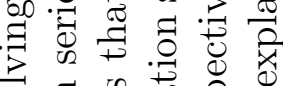

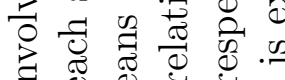

ᄀ०

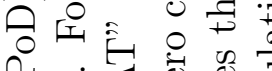

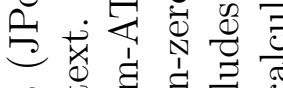

$\pm \stackrel{0}{ \pm}$ 过

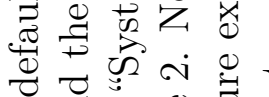

茯

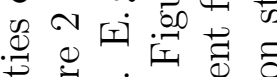

:

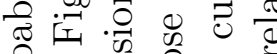

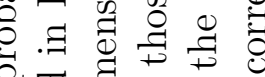

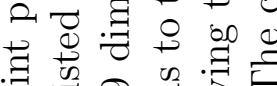

.尹.

$\therefore$ की

نं

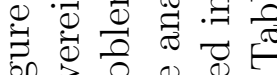

坫
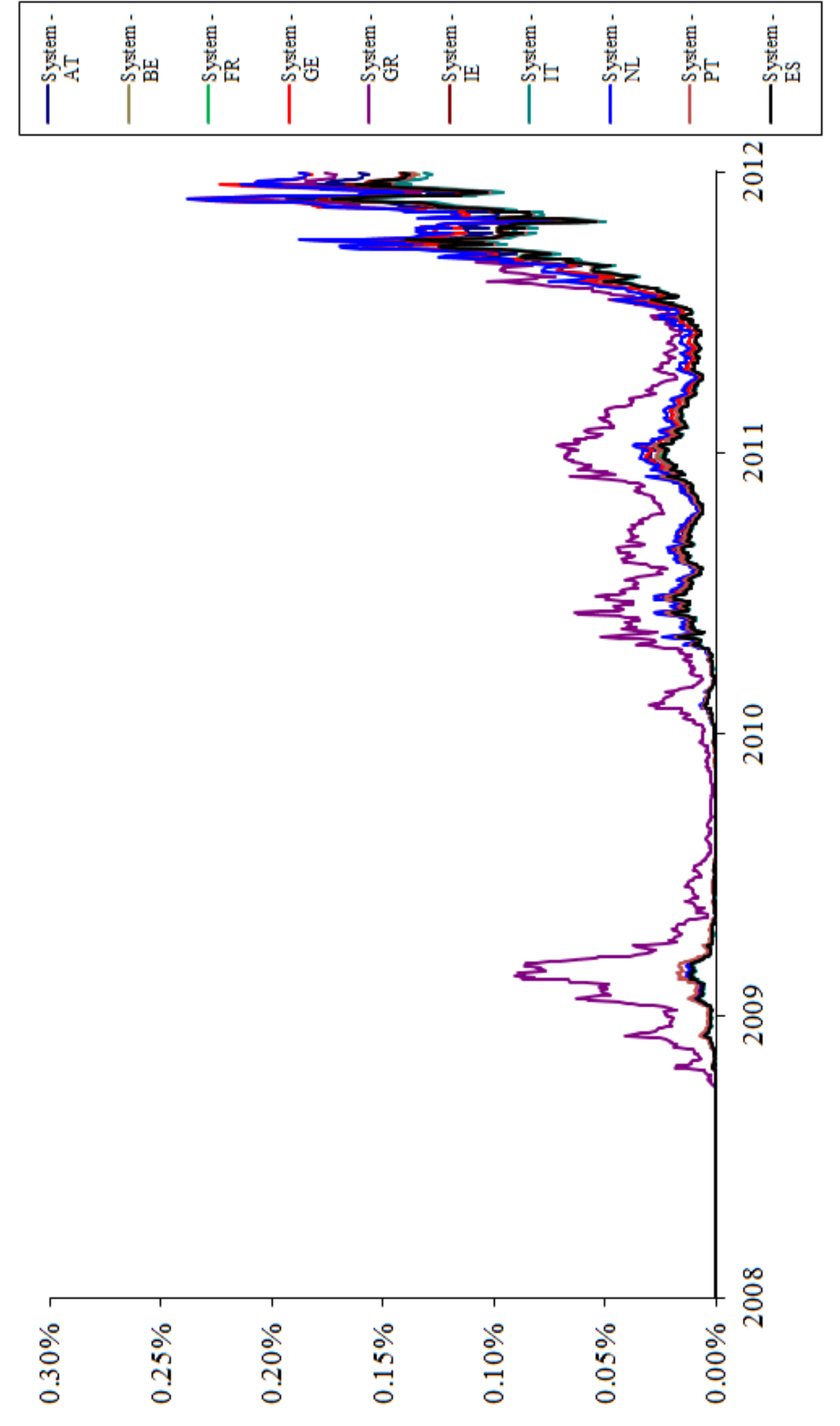


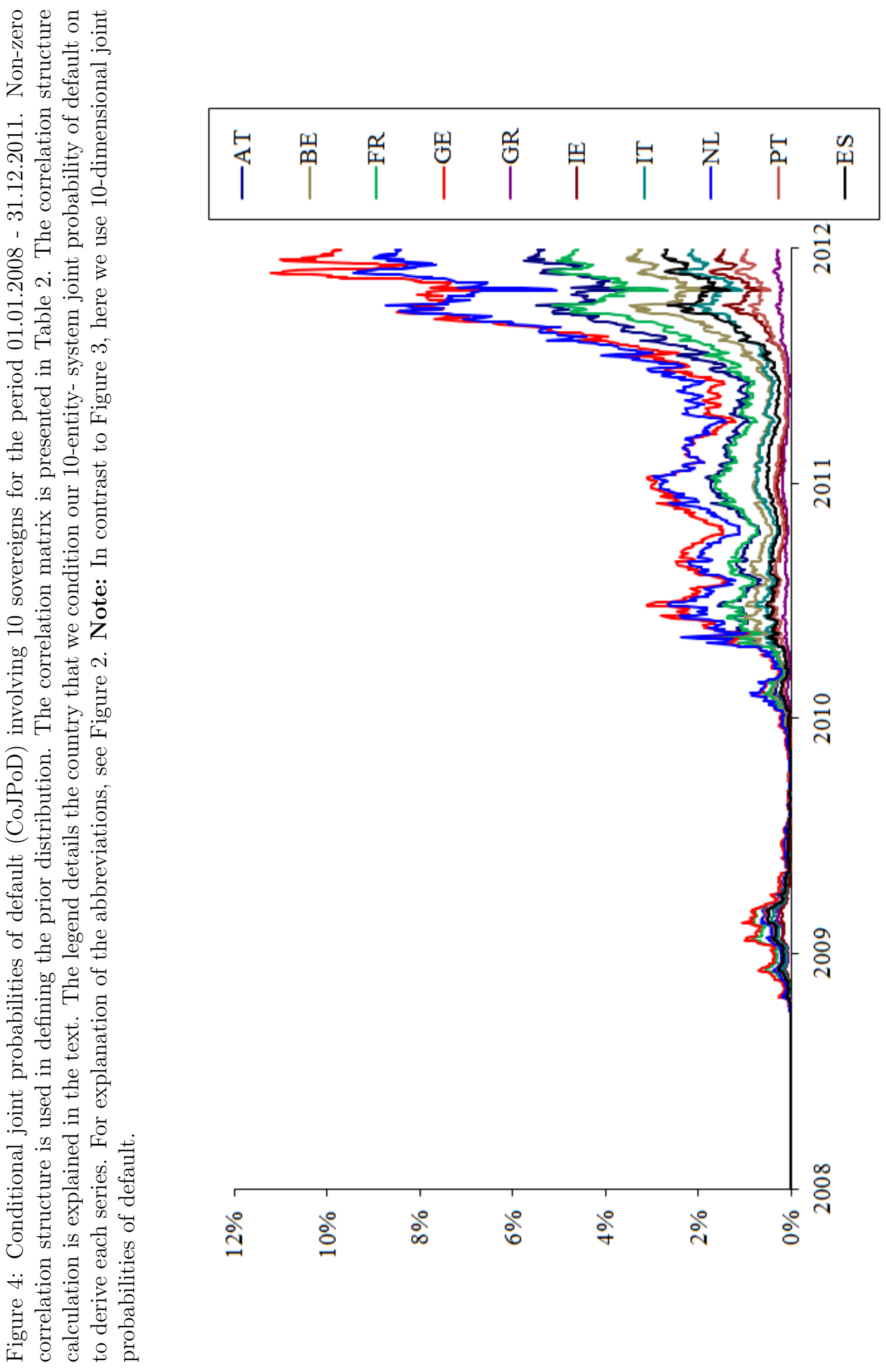




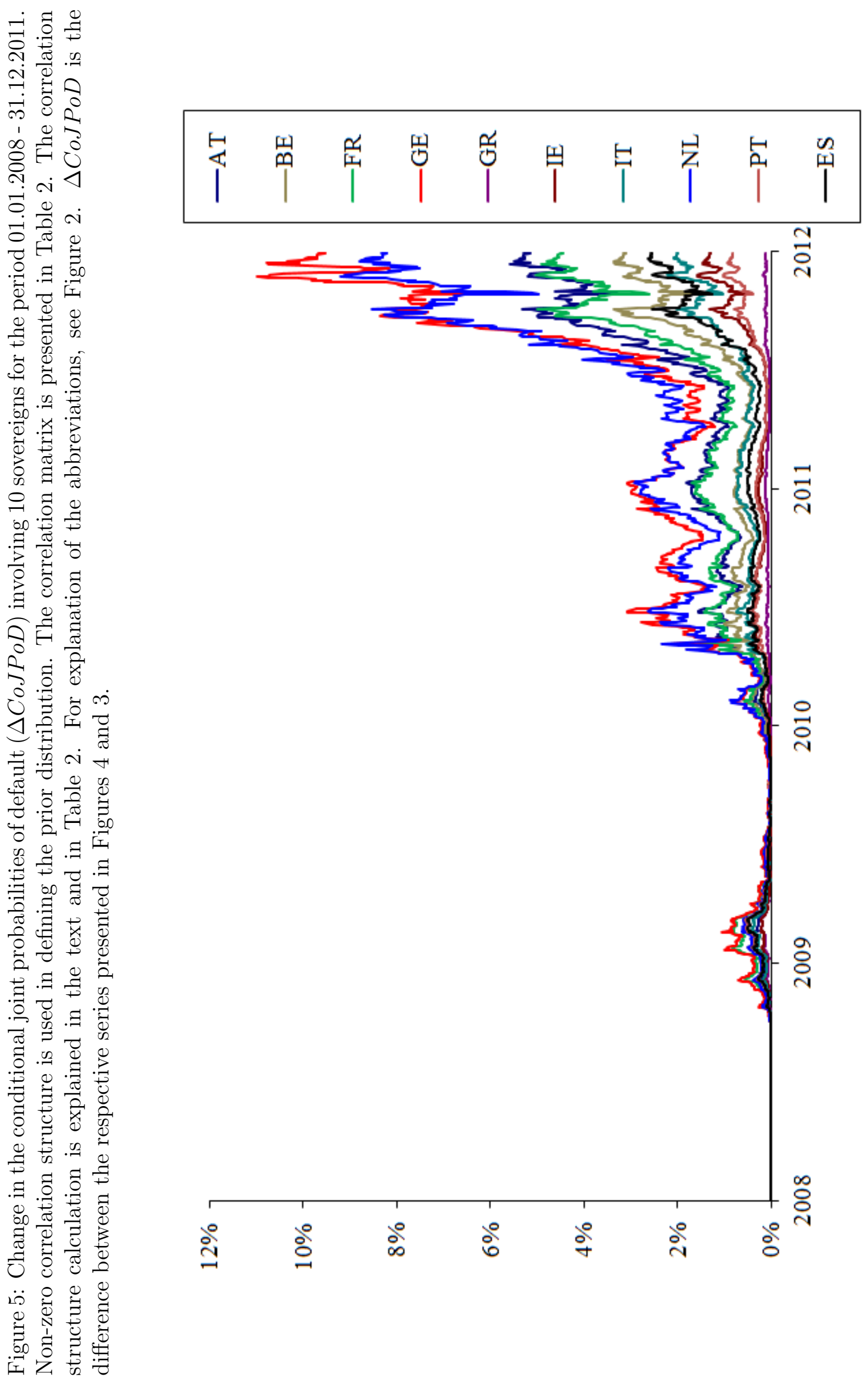




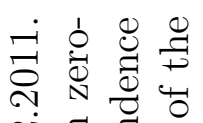

가 륭

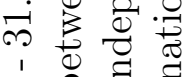

$\infty$ 요

ণิ

○. छ

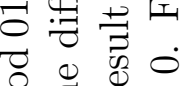

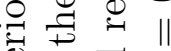

雨

秀

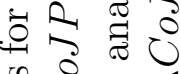

ป 00

$\underset{0}{0} \downarrow$

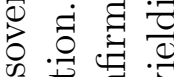

0 号

ob

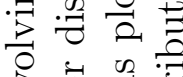

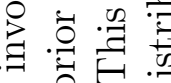

Әิ

$\begin{array}{lll}0 & \cdots & 0 \\ 0 & 0 & 0 \\ 0 & 0 & 0\end{array}$

○.

$\checkmark$ 近 की

녘.引

ثृ

茂

壳

ठ

응 \&

已. 舀

, क 0.

क्षे.

式

o

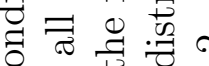

仓 छ

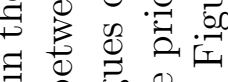

$\stackrel{4}{世}$ 品

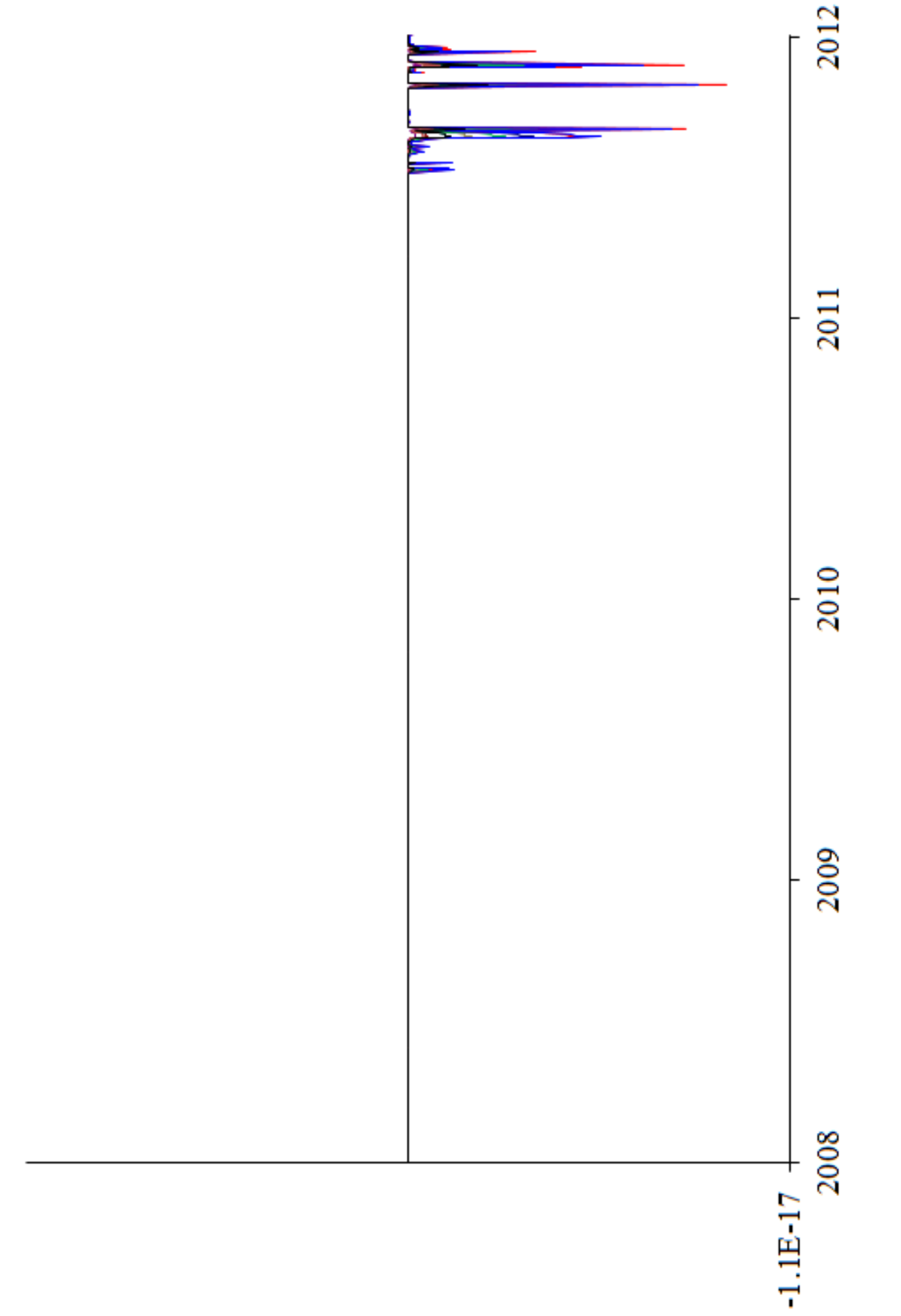

$80 \frac{1}{\square} \frac{8}{\omega}$

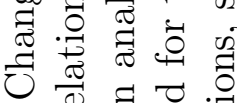

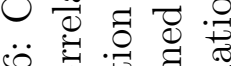

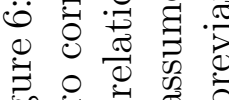

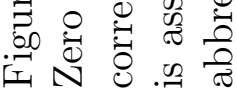



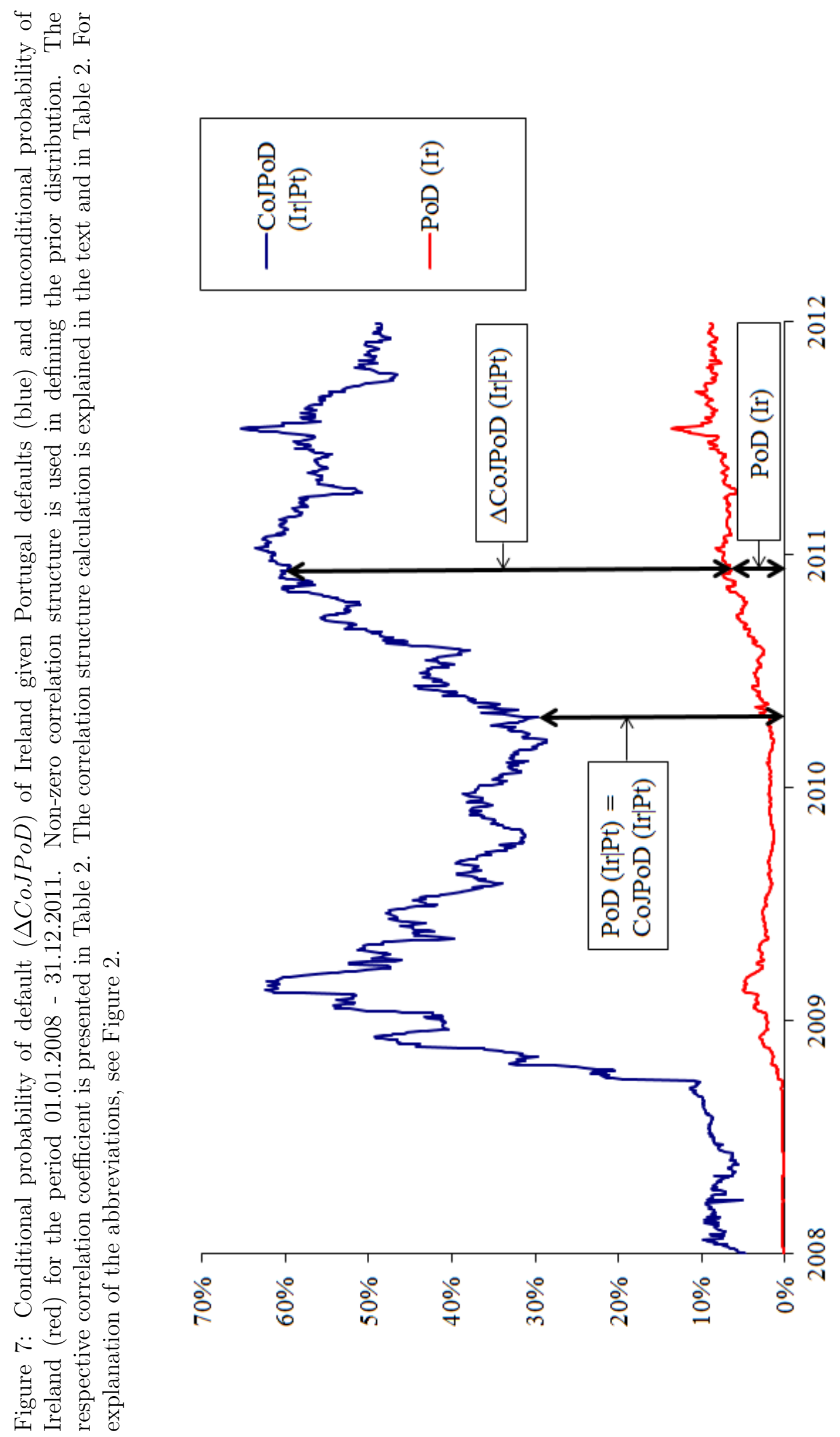


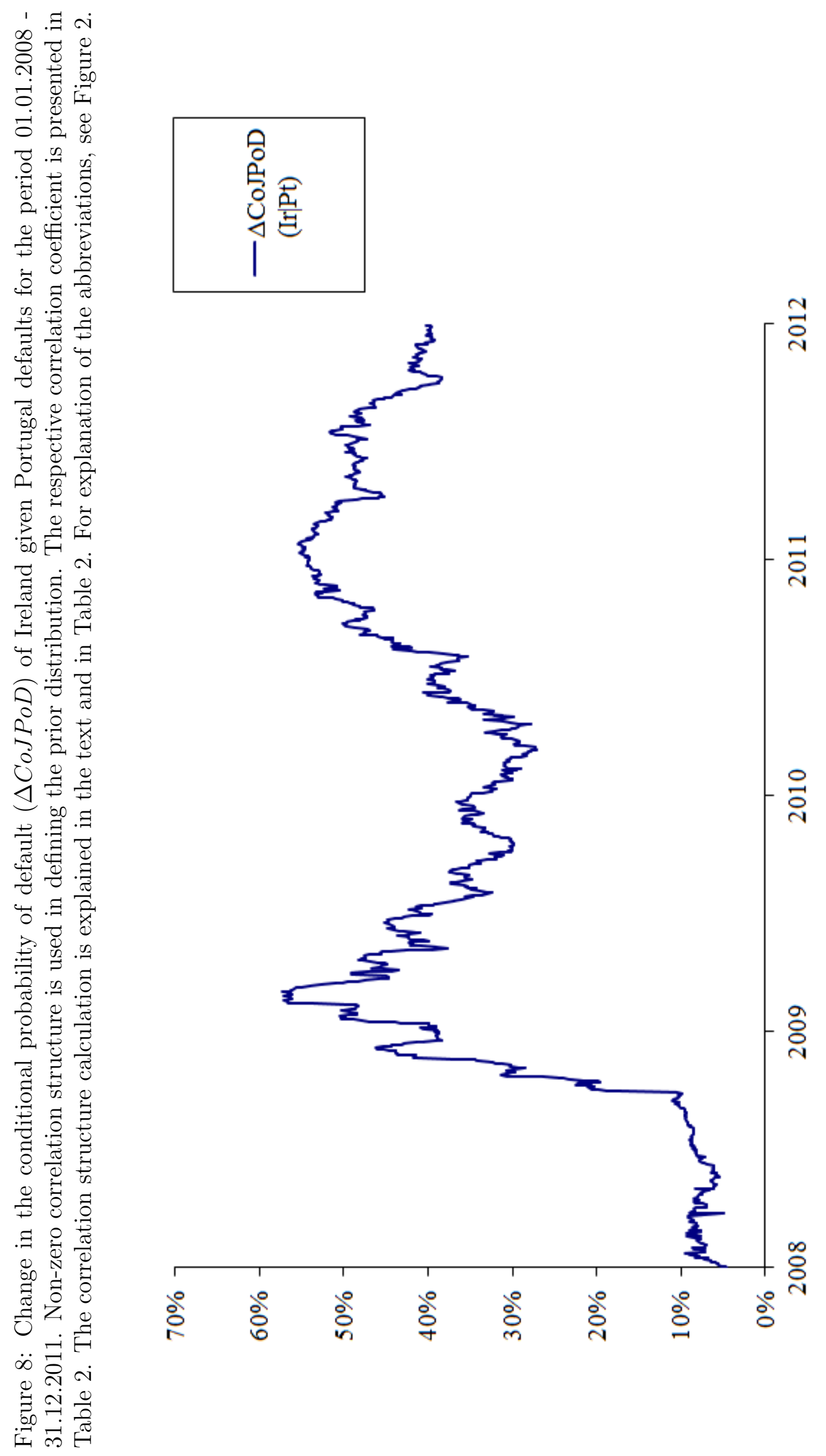




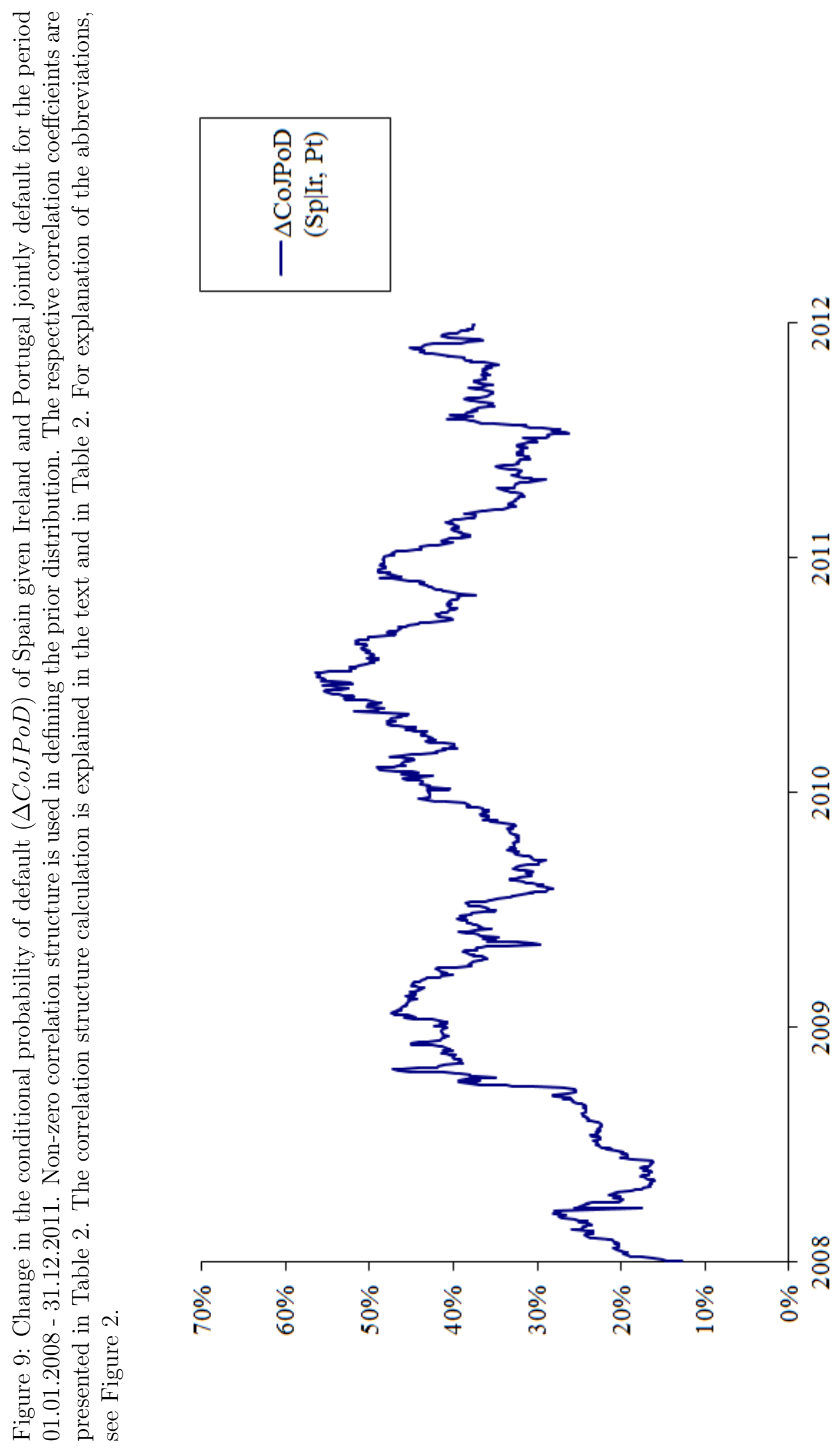




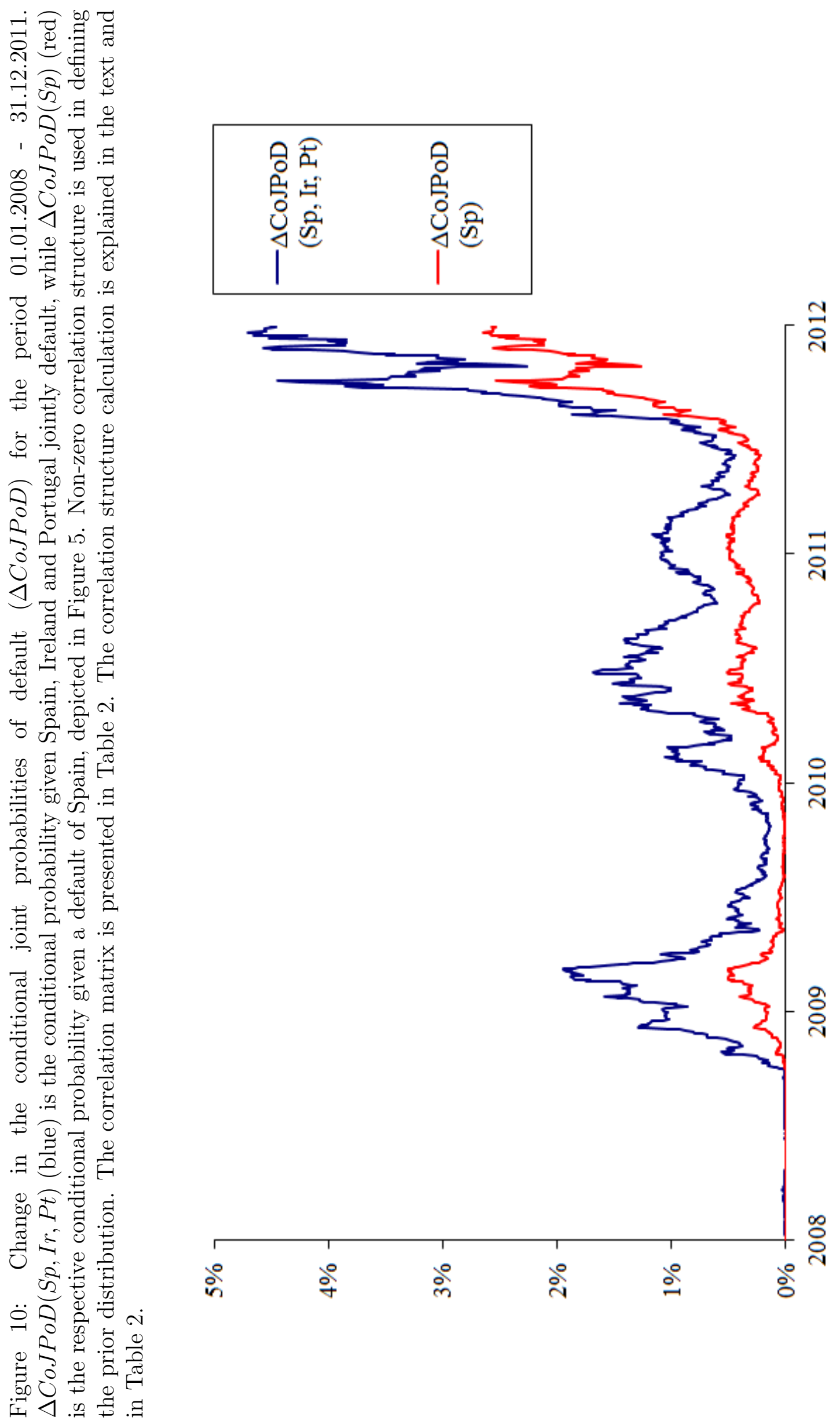




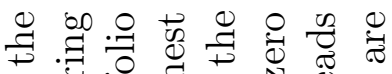

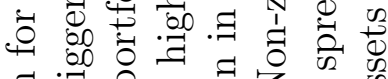

50 궁

嵌

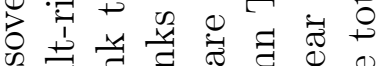

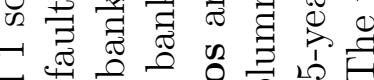

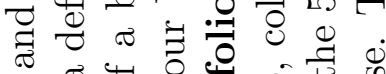

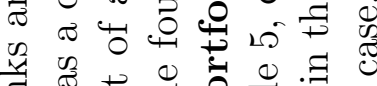

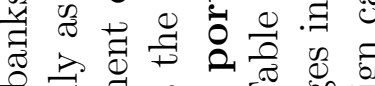

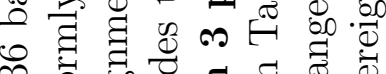

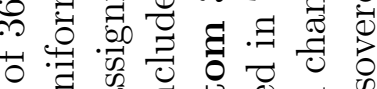

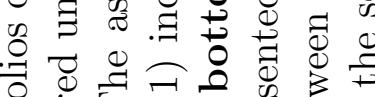

要击

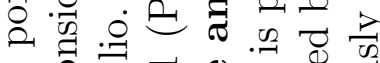

o 000.0

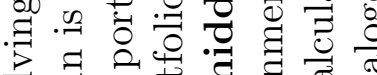

귱

当 की

ลิ.

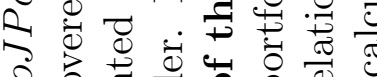

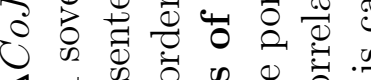

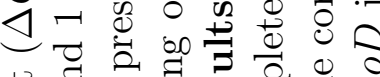

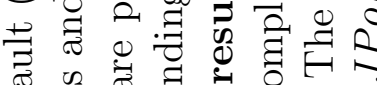

ॠ

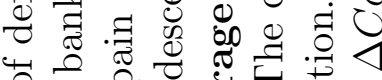

न की

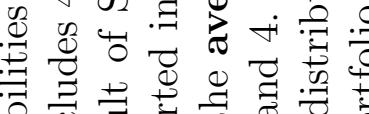

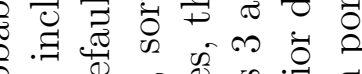

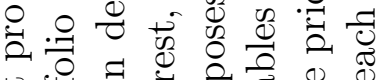

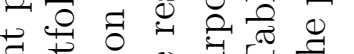

家

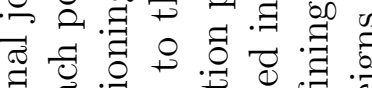

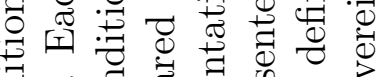

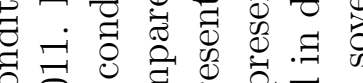

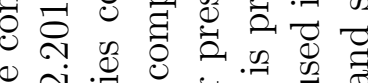

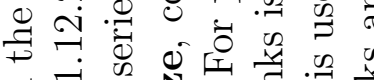

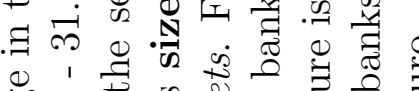

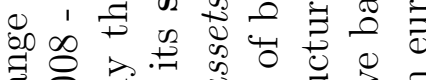
สิ 8 ㄴ.

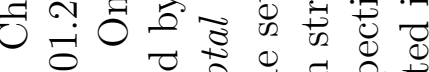

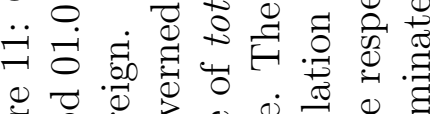

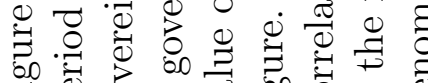

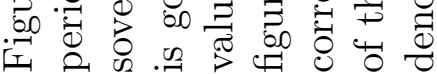

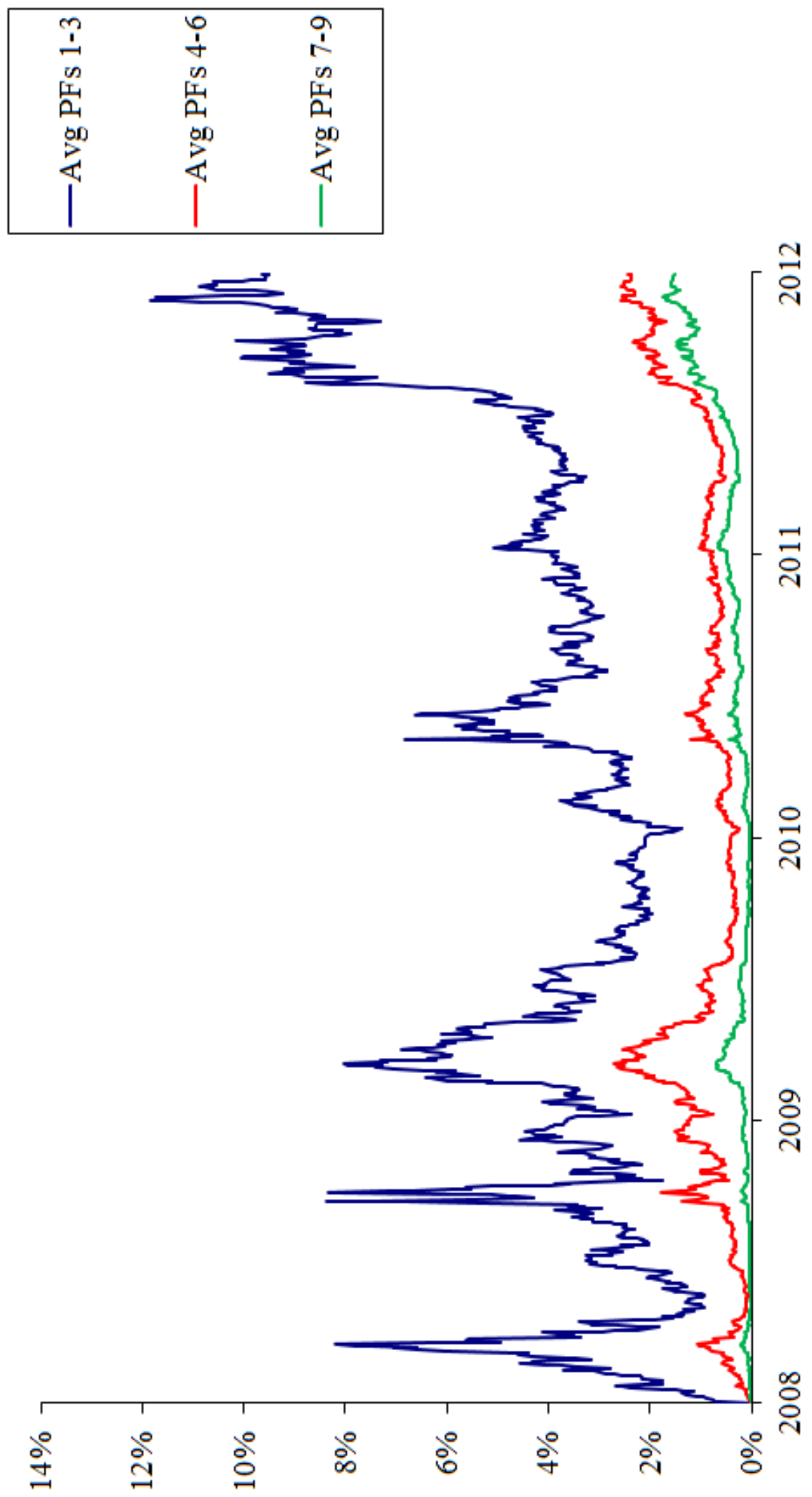




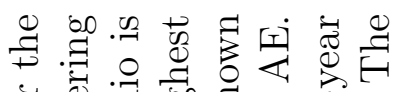

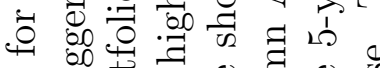

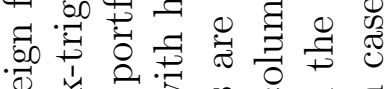

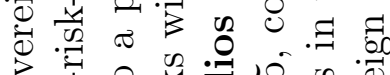

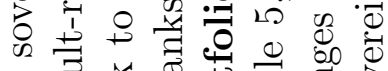

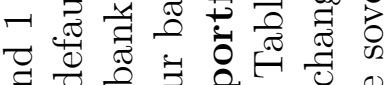

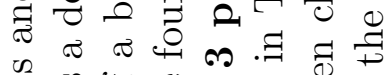

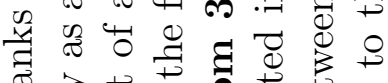

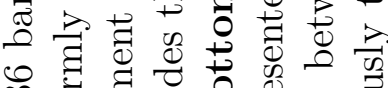

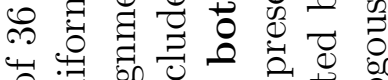
世

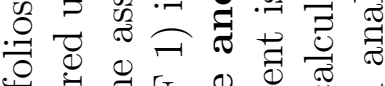

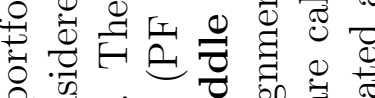
象 $\circ 8 \%$ 읭 : .․

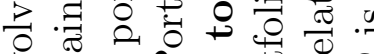

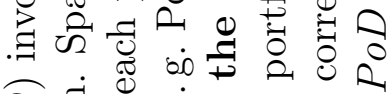

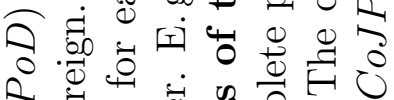

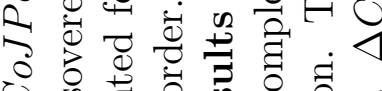
s.

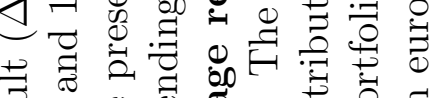

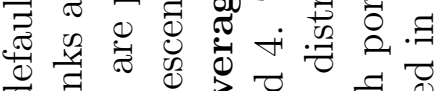

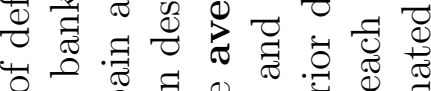

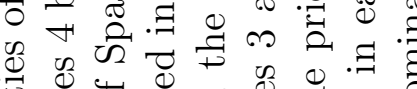
导 过 :

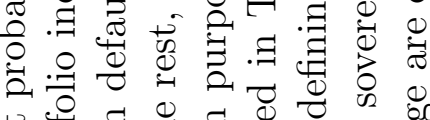

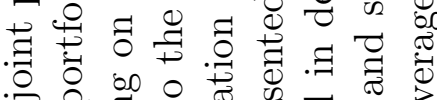
응

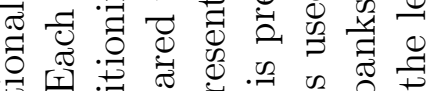

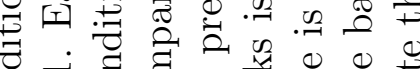

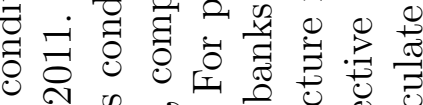
过 两

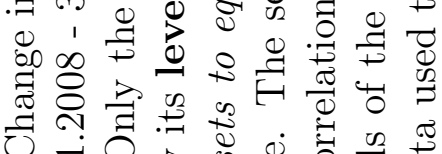

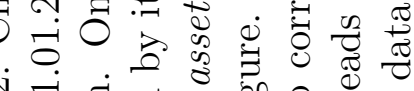

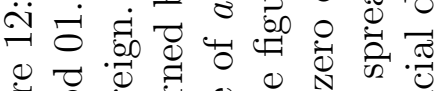

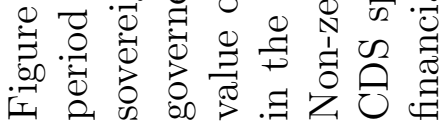

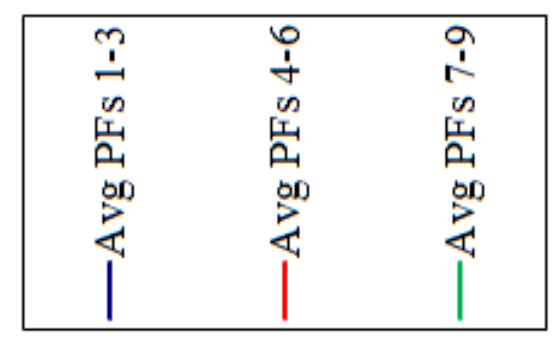

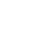




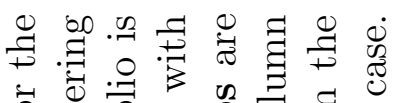

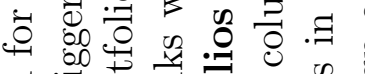

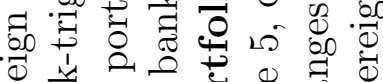

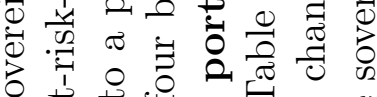
o t

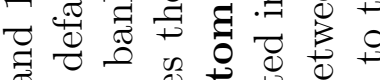

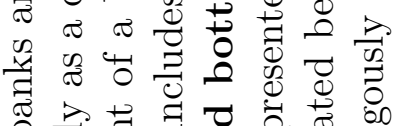

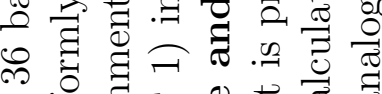
4

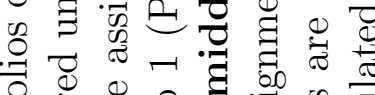

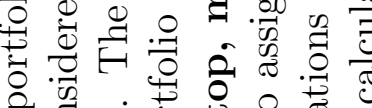

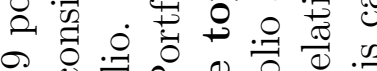

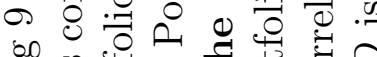

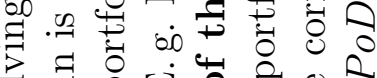

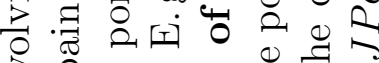

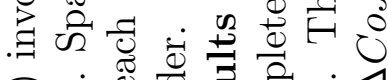

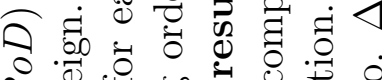
م.

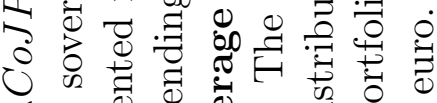
$\unlhd=$ D

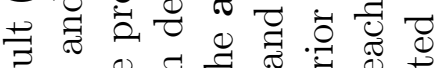

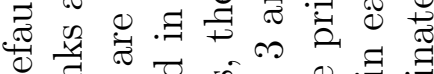

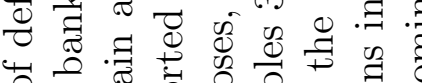

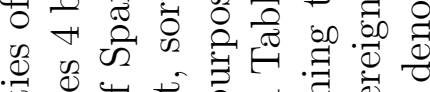

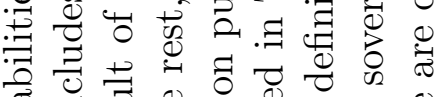

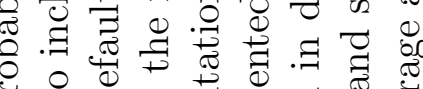

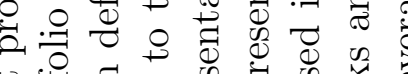

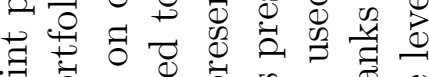

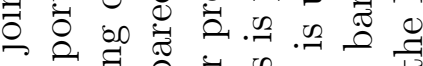

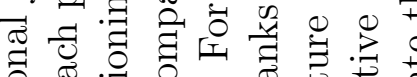

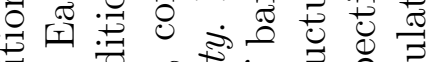

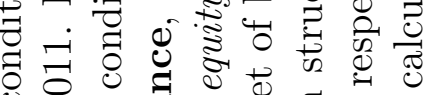

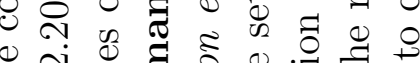

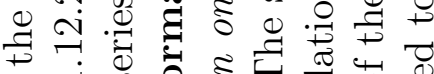
च में क्ष 80000

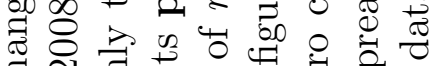
ชั

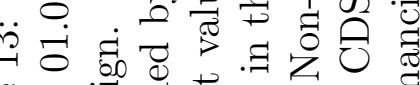

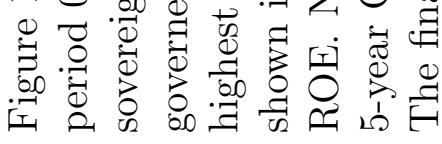
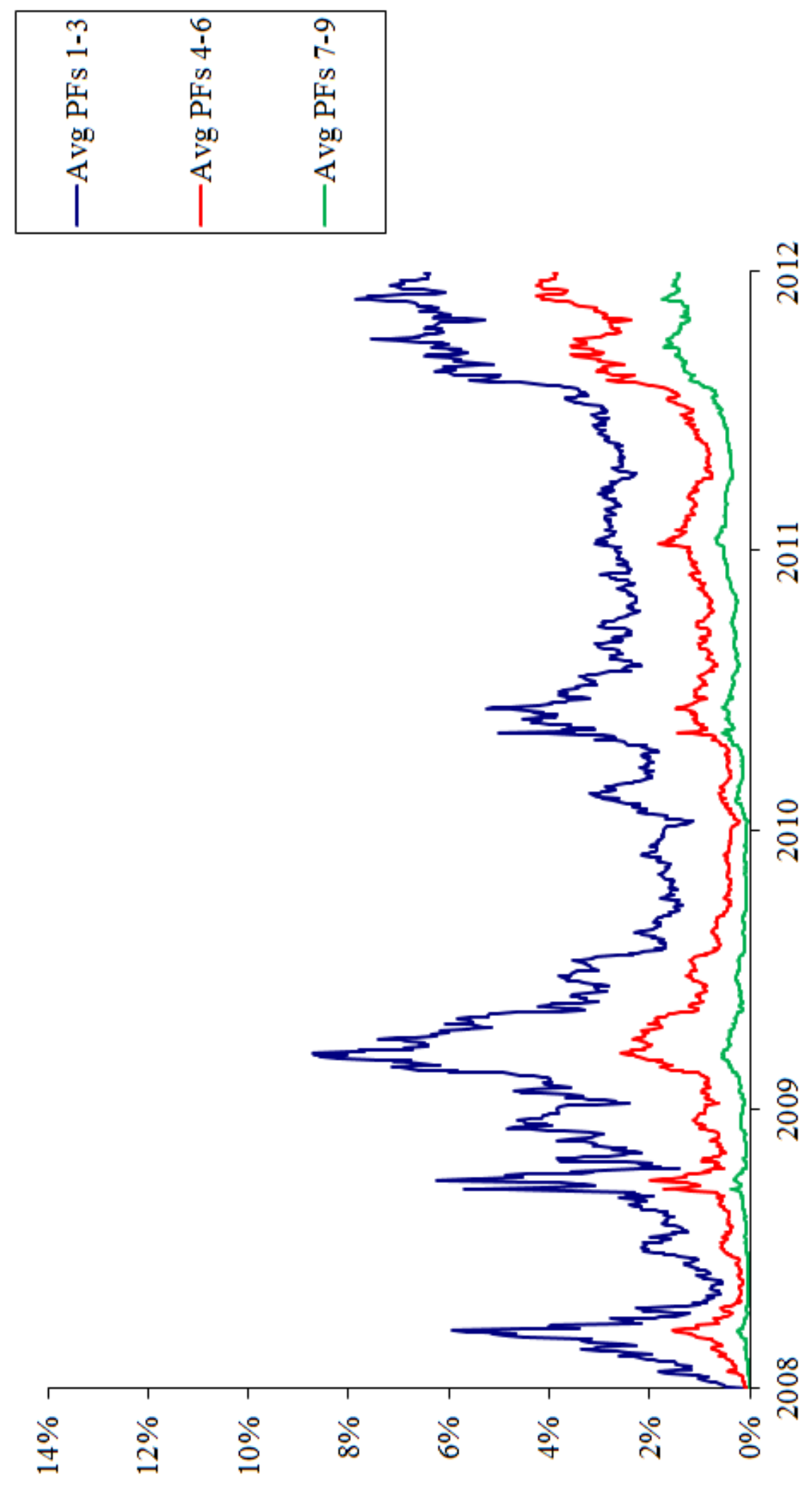


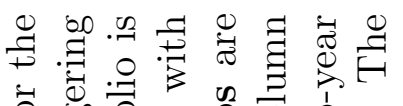

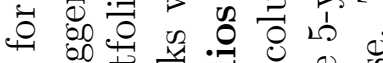

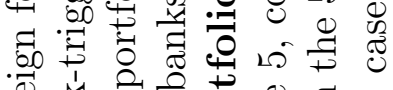

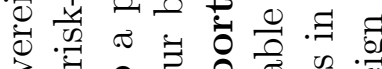

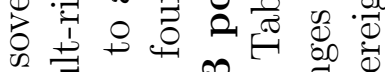

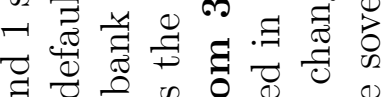
ส

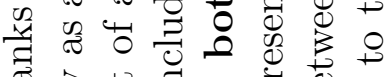
西 격

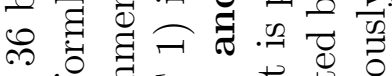

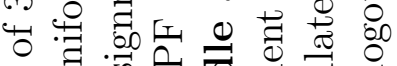

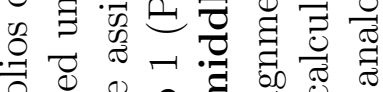

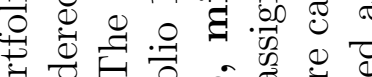

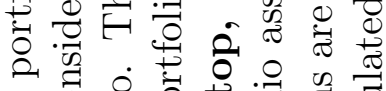

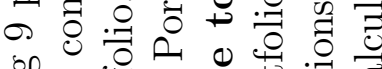

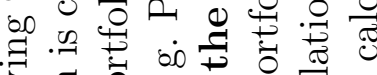

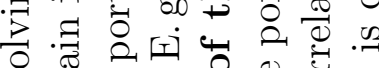

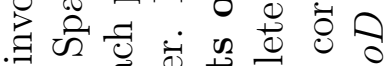
ลิ. 0.0

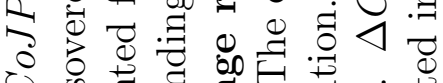
$\checkmark$ 品

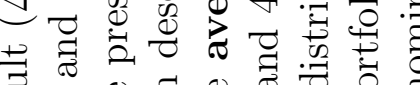

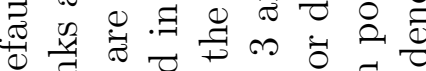
ช

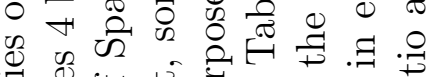

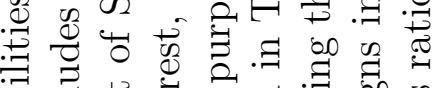

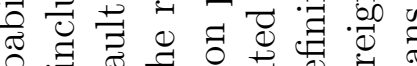
웅

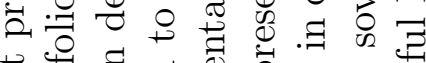

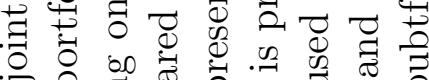

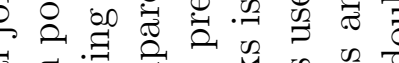

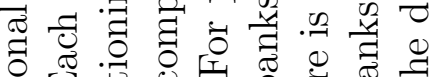

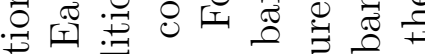
-

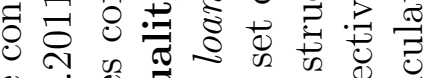
의 의 $\exists \dot{m}$ का

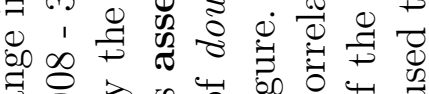

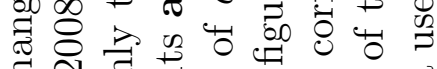
चี

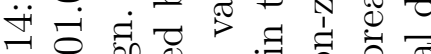

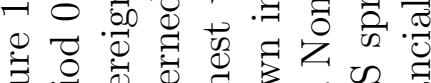

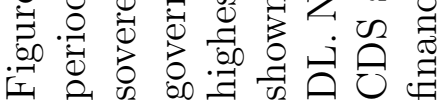
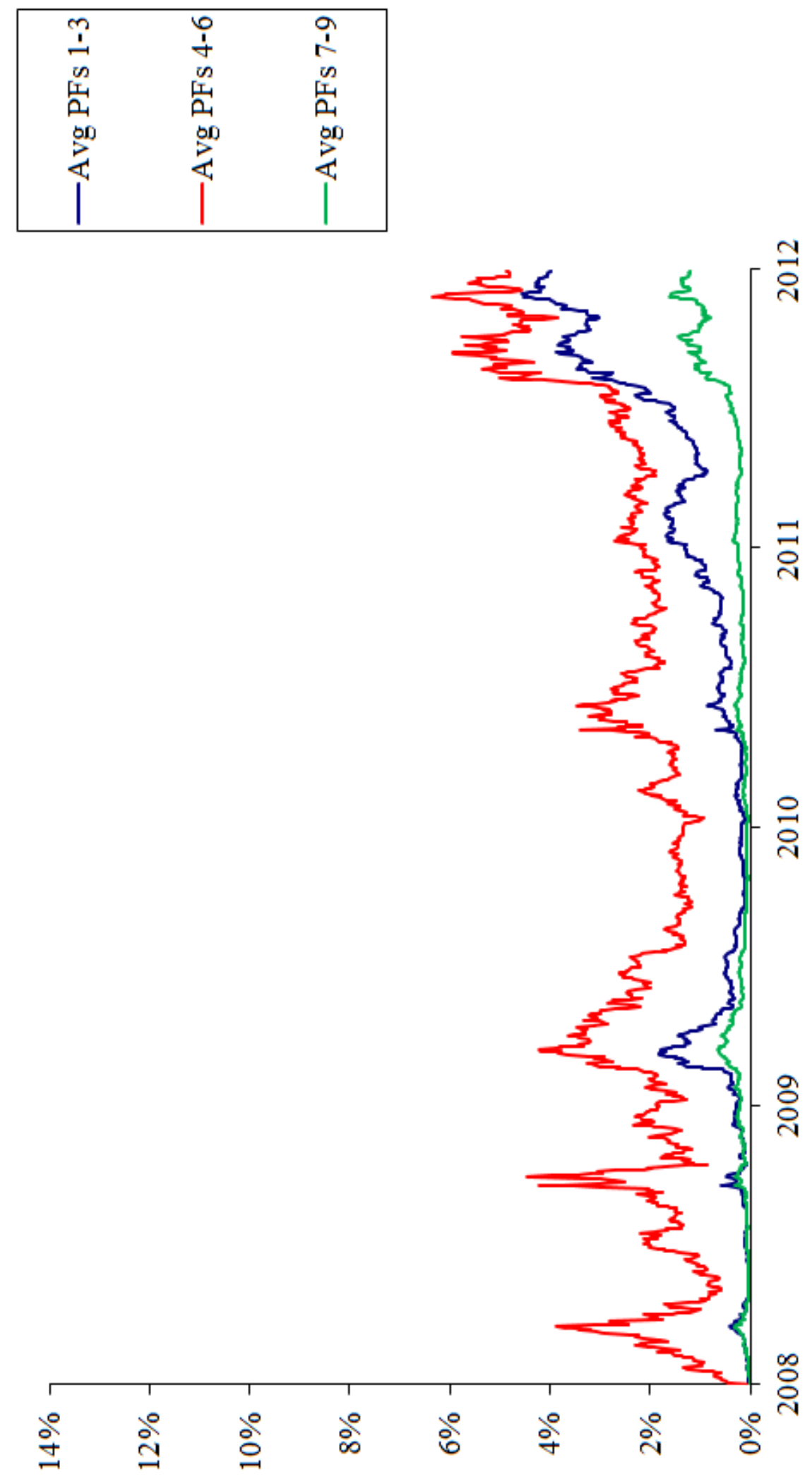


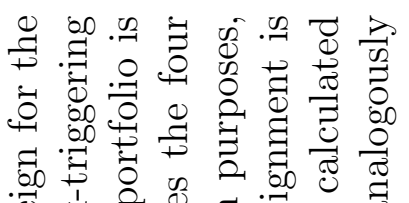

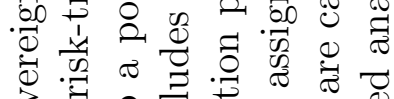

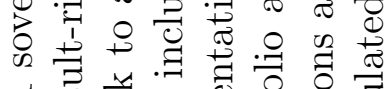

퓨 ส $\approx$ ๘

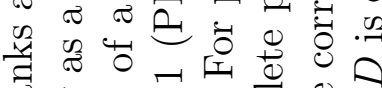

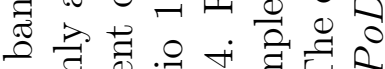

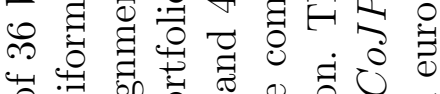

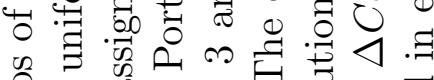

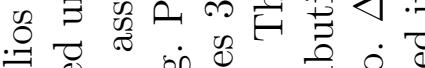

尊造过

¿

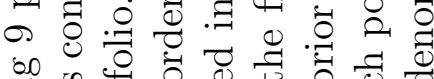

. 에

㱐范

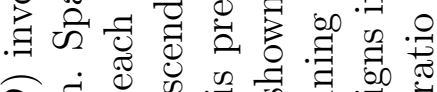

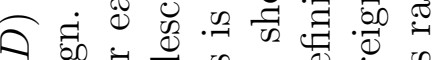

OC.

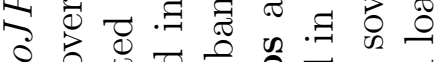

ن

\pm 考

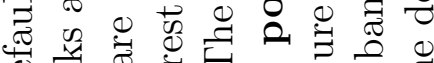

过

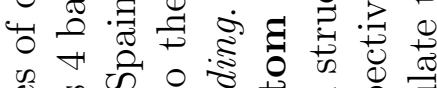

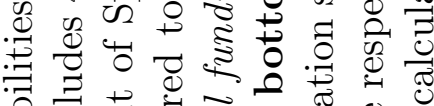

范

己.․ำ

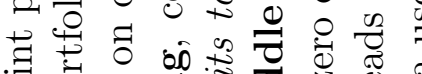

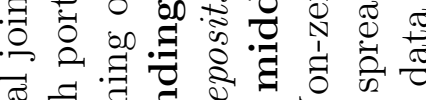

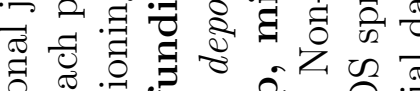

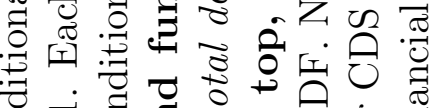

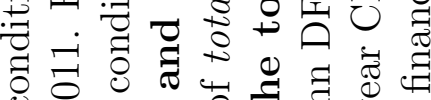

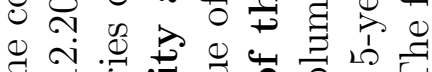

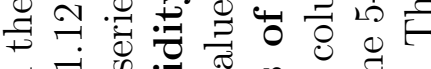

$\exists \pi$ क

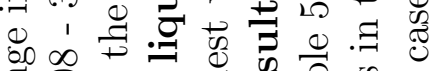

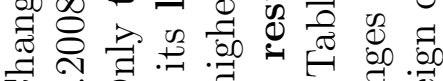

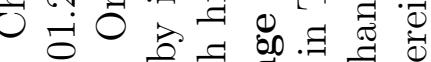

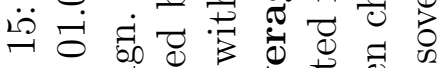

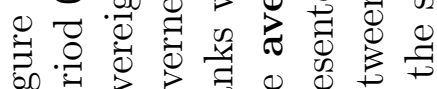

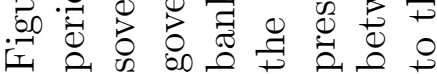
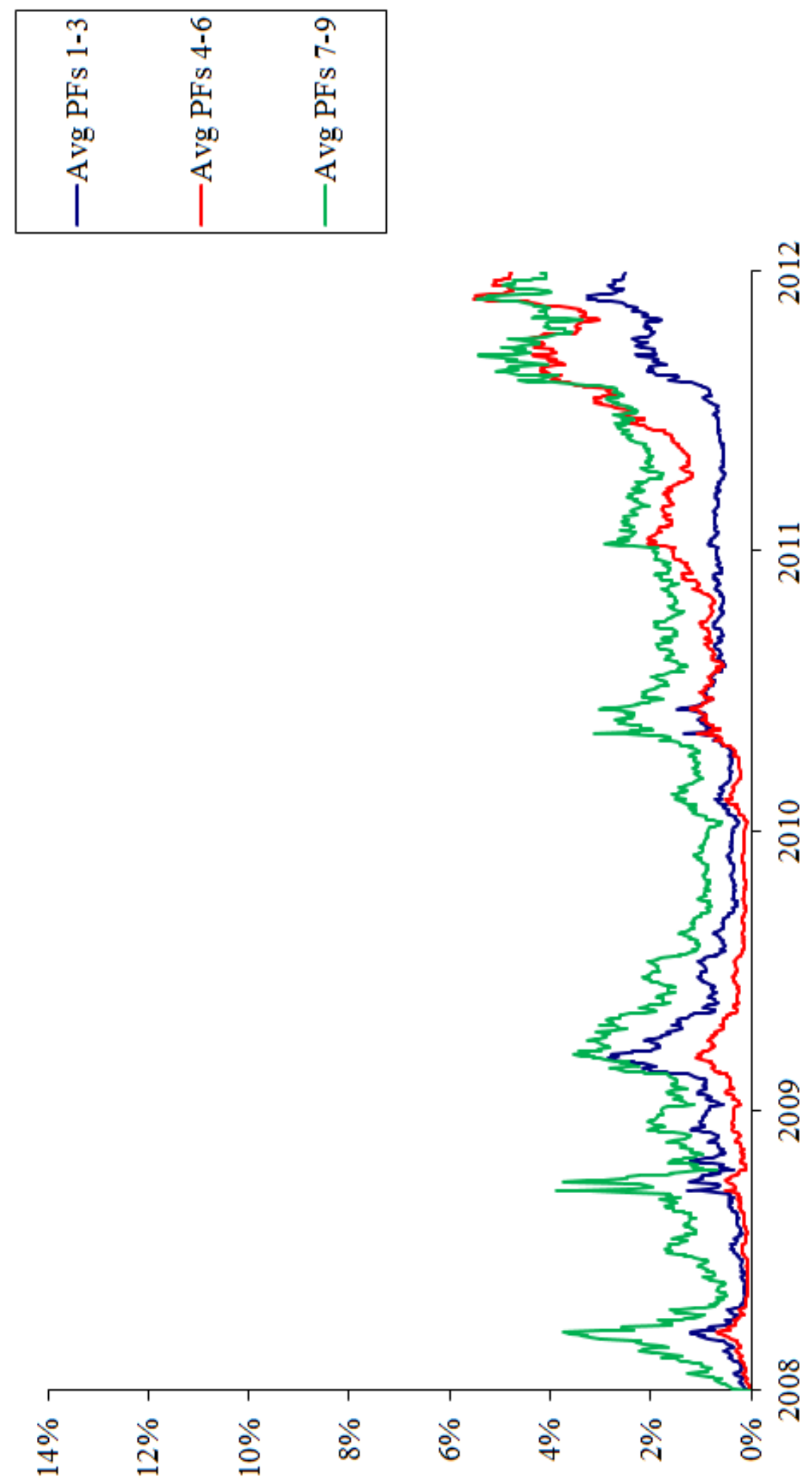


\section{Tables}

Table 1: Descriptive statistics of the 5-year CDS spreads series of Austria (AT), Belgium (BE), France (FR), Germany (GE), Greece (GR), Ireland (IE), Italy (IT), Netherlands (NL), Portugal (PT), Spain (ES). The data are in basis points. Period: 01.01.2008 31.12.2011. Number of observations: 1044.

\begin{tabular}{lccccc}
\hline & AT & BE & FR & GE & GR \\
\hline Minimum & 4.08 & 7.25 & 4.33 & 2.92 & 15.08 \\
Mean & 60.69 & 77.16 & 47.53 & 29.10 & 773.93 \\
Maximum & 215.77 & 303.72 & 186.21 & 90.82 & 11033.74 \\
Standard deviation & 40.73 & 61.26 & 38.36 & 18.95 & 1444.67 \\
Number of observations & 1044 & 1044 & 1044 & 1044 & 1044 \\
\hline \hline & IE & IT & NL & PT & ES \\
\hline Minimum & 9.10 & 13.88 & 4.31 & 12.11 & 11.61 \\
Mean & 234.99 & 116.18 & 34.81 & 231.00 & 121.61 \\
Maximum & 917.55 & 445.26 & 103.63 & 961.47 & 367.64 \\
Standard deviation & 199.37 & 91.20 & 23.39 & 259.73 & 87.88 \\
Number of observations & 1044 & 1044 & 1044 & 1044 & 1044 \\
\hline
\end{tabular}


Table 2: Correlation structure between 10 sovereigns: Austria (AT), Belgium (BE), France (FR), Germany (GE), Greece (GR), Ireland (IE), Italy (IT), Netherlands (NL), Portugal (PT), Spain (ES). Period: 01.01.2008 - 31.12.2011. The correlations are calculated between changes in the 5-year CDS spreads of the sovereigns in the respective column and row.

\begin{tabular}{|l|cccccccccc|}
\hline & AT & BE & FR & GE & GR & IE & IT & NL & PT & ES \\
\hline AT & 1.00 & 0.70 & 0.73 & 0.75 & 0.13 & 0.54 & 0.66 & 0.79 & 0.46 & 0.62 \\
BE & & 1.00 & 0.82 & 0.74 & 0.16 & 0.69 & 0.83 & 0.72 & 0.65 & 0.81 \\
FR & & & 1.00 & 0.82 & 0.22 & 0.63 & 0.81 & 0.73 & 0.60 & 0.76 \\
GE & & & & 1.00 & 0.19 & 0.59 & 0.72 & 0.75 & 0.56 & 0.69 \\
GR & & & & & 1.00 & 0.19 & 0.21 & 0.16 & 0.17 & 0.17 \\
IE & & & & & & 1.00 & 0.71 & 0.55 & 0.77 & 0.74 \\
IT & & & & & & & 1.00 & 0.68 & 0.71 & 0.90 \\
NL & & & & & & & & 1.00 & 0.49 & 0.63 \\
PT & & & & & & & & & 1.00 & 0.73 \\
ES & & & & & & & & & & 1.00 \\
\hline
\end{tabular}


Table 3: List of euro area banks used in our analysis.

\begin{tabular}{|c|c|c|}
\hline \multicolumn{3}{|r|}{ Euro Area Banks } \\
\hline & Country code & Name \\
\hline 1 & $\mathrm{AT}$ & Erste Group Bank AG \\
\hline 2 & AT & Raiffeisen Bank International Austria \\
\hline 3 & $\mathrm{BE}$ & Dexia SA \\
\hline 4 & $\mathrm{BE}$ & KBC Groep NV \\
\hline 5 & DE & Bayerische Landesbank \\
\hline 6 & $\mathrm{DE}$ & Commerzbank AG \\
\hline 7 & $\mathrm{DE}$ & Deutsche Bank AG \\
\hline 8 & DE & Landesbank Berlin Holding AG \\
\hline 9 & ES & Banco Bilbao Vizcaya Argentaria \\
\hline 10 & ES & Banco de Sabadell SA \\
\hline 11 & ES & Banco Santander SA \\
\hline 12 & FR & BNP Paribas \\
\hline 13 & $\mathrm{FR}$ & Credit Agricole SA \\
\hline 14 & FR & Natixis \\
\hline 15 & FR & Societe Generale \\
\hline 16 & $\mathrm{IE}$ & Allied Irish Banks PLC \\
\hline 17 & IE & Governor \& Co of the Bank of Ireland \\
\hline 18 & IE & Irish Life and Permanent \\
\hline 19 & IT & Banca Monte dei Paschi di Siena \\
\hline 20 & IT & Banca Popolare di Milano \\
\hline 21 & IT & Banco Popolare SC \\
\hline 22 & IT & Intesa Sanpaolo SpA \\
\hline 23 & $\mathrm{IT}$ & UniCredit SpA \\
\hline 24 & NL & ING Groep NV \\
\hline 25 & NL & Rabobank \\
\hline 26 & NL & SNS Bank Netherlands \\
\hline 27 & $\mathrm{PT}$ & Banco Comercial Portugues SA \\
\hline 28 & PT & Espirito Santo Financial Group \\
\hline
\end{tabular}

Table 4: List of additional non-euro area European Union banks used in our analysis.

\begin{tabular}{|c|c|c|}
\hline \multicolumn{3}{|c|}{ Other European Union Banks } \\
\hline & Country code & Name \\
\hline 1 & DK & Danske Bank A/S \\
2 & GB & Barclays PLC \\
3 & GB & HSBC Holdings PLC \\
4 & GB & Lloyds Banking Group PLC \\
5 & GB & Royal Bank of Scotland Group \\
6 & GB & Standard Chartered PLC \\
7 & SE & Nordea Bank AB \\
8 & SE & Skandinaviska Enskilda Banken \\
\hline
\end{tabular}


Table 5: Ranking assignment in descending order of the 36 banks used in our analysis with respect to 10 financial characteristics. The numbers in the columns for the financial characteristics come from the ordering in Tables 3 and 4. The values from 29 to 36 are given to the non-euro area European Union banks in the same order as in Table 4. PF 1 to PF 9 list the 4 banks that are included in the final 5-entity portfolios for each financial characteristic. The abbreviations stand for, as follows: total assets (TA), return on equity (ROE), return on assets (ROA), net interest margin (NIM), efficiency ratio (ER), deposits-to-funding (DF) ratio, assets-to-equity (AE) ratio, loan-loss-provisionsto-net-interest-income (LLP-to-NII) ratio, non-performing-loans-to-total-loans ("doubtful loans", DL) ratio, net-loans-to-total-assets (NL-to-TA) ratio.

\begin{tabular}{|c|c|c|c|c|c|c|c|c|c|c|c|}
\hline & & \multicolumn{10}{|c|}{ Financial Characteristics } \\
\hline Ranking & Portfolios & $\mathrm{TA}$ & $\mathrm{ROE}$ & ROA & NIM & ER & $\mathrm{DF}$ & $\mathrm{AE}$ & LLP-to-NII & $\mathrm{DL}$ & NL-to-TA \\
\hline 1 & \multirow{4}{*}{ PF 1} & 33 & 11 & 2 & 2 & 4 & 31 & 3 & 16 & 16 & 26 \\
\hline 2 & & 12 & 23 & 8 & 1 & 16 & 34 & 8 & 17 & 21 & 27 \\
\hline 3 & & 7 & 33 & 11 & 9 & 14 & 18 & 7 & 18 & 19 & 10 \\
\hline 4 & & 31 & 31 & 10 & 11 & 29 & 24 & 18 & 32 & 23 & 25 \\
\hline 5 & \multirow{4}{*}{ PF 2} & 30 & 7 & 9 & 34 & 8 & 1 & 26 & 3 & 17 & 20 \\
\hline 6 & & 13 & 9 & 35 & 20 & 6 & 7 & 24 & 26 & 22 & 17 \\
\hline 7 & & 24 & 34 & 22 & 19 & 20 & 23 & 6 & 33 & 1 & 21 \\
\hline 8 & & 11 & 30 & 19 & 31 & 32 & 19 & 13 & 5 & 32 & 19 \\
\hline 9 & \multirow{4}{*}{ PF 3} & 15 & 32 & 1 & 22 & 21 & 4 & 29 & 27 & 2 & 16 \\
\hline 10 & & 23 & 22 & 36 & 10 & 19 & 2 & 30 & 31 & 8 & 28 \\
\hline 11 & & 32 & 12 & 30 & 23 & 33 & 25 & 5 & 14 & 6 & 2 \\
\hline 12 & & 6 & 25 & 20 & 21 & 13 & 32 & 12 & 30 & 15 & 9 \\
\hline 13 & \multirow{4}{*}{$\mathrm{PF} 4$} & 22 & 15 & 31 & 16 & 1 & 27 & 32 & 24 & 33 & 32 \\
\hline 14 & & 25 & 6 & 34 & 4 & 22 & 11 & 17 & 21 & 30 & 1 \\
\hline 15 & & 3 & 4 & 27 & 27 & 24 & 9 & 14 & 6 & 12 & 11 \\
\hline 16 & & 9 & 1 & 12 & 28 & 18 & 20 & 36 & 15 & 13 & 23 \\
\hline 17 & \multirow{4}{*}{ PF 5} & 35 & 35 & 24 & 32 & 15 & 10 & 35 & 1 & 10 & 22 \\
\hline 18 & & 14 & 29 & 15 & 17 & 25 & 16 & 15 & 23 & 4 & 29 \\
\hline 19 & & 29 & 19 & 28 & 25 & 27 & 17 & 16 & 2 & 26 & 3 \\
\hline 20 & & 5 & 2 & 23 & 30 & 26 & 33 & 33 & 10 & 9 & 35 \\
\hline 21 & \multirow{4}{*}{ PF 6} & 4 & 3 & 6 & 33 & 23 & 36 & 4 & 12 & 14 & 18 \\
\hline 22 & & 34 & 13 & 21 & 35 & 28 & 21 & 31 & 11 & 29 & 24 \\
\hline 23 & & 36 & 24 & 7 & 29 & 12 & 26 & 9 & 9 & 27 & 36 \\
\hline 24 & & 19 & 21 & 25 & 26 & 36 & 35 & 25 & 28 & 11 & 5 \\
\hline 25 & \multirow{4}{*}{ PF 7} & 1 & 36 & 29 & 12 & 30 & 6 & 10 & 19 & 31 & 34 \\
\hline 26 & & 17 & 27 & 13 & 24 & 2 & 22 & 11 & 13 & 5 & 6 \\
\hline 27 & & 16 & 10 & 32 & 13 & 34 & 30 & 34 & 22 & 7 & 4 \\
\hline 28 & & 8 & 28 & 14 & 15 & 31 & 13 & 23 & 20 & 20 & 31 \\
\hline 29 & \multirow{4}{*}{ PF 8} & 21 & 20 & 18 & 36 & 35 & 28 & 27 & 29 & 18 & 33 \\
\hline 30 & & 2 & 8 & 5 & 6 & 10 & 29 & 1 & 36 & 34 & 15 \\
\hline 31 & & 27 & 14 & 26 & 7 & 5 & 15 & 19 & 4 & 25 & 8 \\
\hline 32 & & 10 & 18 & 17 & 3 & 9 & 8 & 28 & 35 & 24 & 12 \\
\hline 33 & \multirow{4}{*}{ PF 9} & 26 & 26 & 4 & 8 & 11 & 5 & 20 & 25 & 28 & 13 \\
\hline 34 & & 28 & 17 & 3 & 5 & 17 & 12 & 2 & 34 & 36 & 30 \\
\hline 35 & & 18 & 5 & 33 & 14 & 7 & 3 & 22 & 8 & 35 & 14 \\
\hline 36 & & 20 & 16 & 16 & 18 & 3 & 14 & 21 & 7 & 3 & 7 \\
\hline
\end{tabular}

